\title{
UN haLLAZgo DEL PERÍODO FORMATIVO EN EL VALLE DE ASIA
}

\author{
Rommel Ángeles Falcón
}

\section{RESUMEN}

Se presenta un contexto funerario procedente del valle bajo de Asia, ubicado a 100 kilómetros al sur de Lima. Los materiales asociados indican la presencia de puntas de obsidiana, esculturas de hueso y espejo de antracita, entre otros vestigios. Esto nos lleva a plantear que el valle de Asia no fue ajeno al tráfico de ideologías, o la interacción de las sociedades costeñas y serranas durante este período donde los aspectos ideológicos jugaron un rol fundamental.

Se presenta del mismo modo las características arquitectónicas y el patrón de asentamiento del valle durante el período Formativo, se señala también las diferencias existentes entre la costa de Lima y la costa norcentral, determinándose en aquélla la ausencia de arquitectura pública monumental.

\section{ABSTRACT}

It is presented one funeral context from the low valley of Asia, located at 100 kilometers in the south of Lima. The associated materials indicate the presence of obsidian points, bone sculptures and anthracite mirror, between other vestiges. This takes us to plan that the Asia valley was not strange to ideologies traffic or the interaction of coast and highland societies during this period where ideological aspects played a fundamental role.

It is presented in the same way the architectonic characteristics and the settlement pattern of the valley during the Formative period, it is pointed too, the existing differences between Lima coast and the north central coast, determined in that one the absence of monumental public architecture.

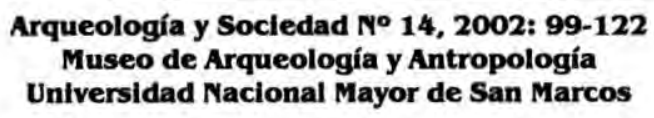


$\mathrm{D}$ urante labores de extracción de tierra en una cantera ubicada a la altura del kilómetro 101 de la carretera Panamericana Sur, en el valle de Asia, un hallazgo de material arqueológico fue reportado al Museo Municipal de Asia; se trataba de un lote de material lítico donde destacaba la presencia de puntas de proyectil de obsidiana, un espejo de antracita y un hacha de piedra pulida. Posteriores revisiones del sitio permitieron recuperar información complementaria acerca del contexto y demás asociaciones; se trataba al parecer de una tumba disturbada correspondiente al período Formativo. Hallazgos con materiales de este tipo son excepcionales y el reporte de contextos correspondientes a este período no son muy conocidos para el valle de Asia, a pesar de la gran cantidad de sitios existentes.

\section{EL VALLE DE ASIA}

El valle de Asia se ubica al sur de Lima entre los valles de Mala por el norte y Cañete por el sur. Destaca por su aridez, el amplio cono de deyección y sus playas arenosas frente a la isla de Asia (Plano 1).

El valle bajo es de clima árido y semicálido; presenta un área hidromórfica y salinizada que comprende las partes bajas alrededor de los pueblos de Rosario de Asia y Capilla de Asia. Presenta, asimismo, suelos aluviales y un relieve depresionado. En estos sectores la vegetación es hidrofítica y halofítica, predominando la "grama salada" (Distichlis spicata), además de la Salicornia fruticosa, así como otros arbustos; esta vegetación es aprovechada cuando tiene sus brotes tiernos por el ganado caprino y equino.

Se presentan áreas con la capa freática superficial donde se desarrollan en baja pro- porción plantas adaptadas a este medio ambiente tales como el "junco" (Scyrpus sp.) (ONERN 1976: 44).

Por este motivo la agricultura es bastante difícil, utilizándose para tal efecto el agua del subsuelo. Las pampas eriazas tienen poco uso por la falta de agua de riego. Los suelos tienen un origen aluvial, coluvial y eólico.

El valle medio es estrecho y de bordes pendientes, ensanchándose a la altura de las localidades de Coayllo, Uquira y Omas.

La información arqueológica indica que el valle bajo destaca por la gran cantidad de sitios correspondientes a los períodos Precerámico y Formativo (Engel 1963, 1987). Precisamente el sitio Asia Unidad 1 , fue uno de los primeros en ser excavados, del que se obtuvo una rica información acerca de la arquitectura, dieta y patrones funerarios del período Precerámico Tardío. Huaca Larga es un sitio de grandes dimensiones donde destaca un denso basural de este período.

Los sitios correspondientes al Formativo se caracterizan por formar acumulaciones de conchas y desechos orgánicos que se ubican a unos 2 kilómetros frente al litoral. De éstos se han excavado dos tumbas de este período (Engel: 1987). Ciertamente entre los kilómetros 97 al 101 una serie de montículos ocupan una franja de hasta 400 metros; se componen de grandes acumulaciones de basura donde destacan conchas, cerámica y material orgánico.

Los montículos tienen diversa altura y tamaño; se distinguen por constituirse en acumulaciones de basura prehispánica donde destaca la presencia de fragmentos de ollas monocromas sin cuello con borde en forma 


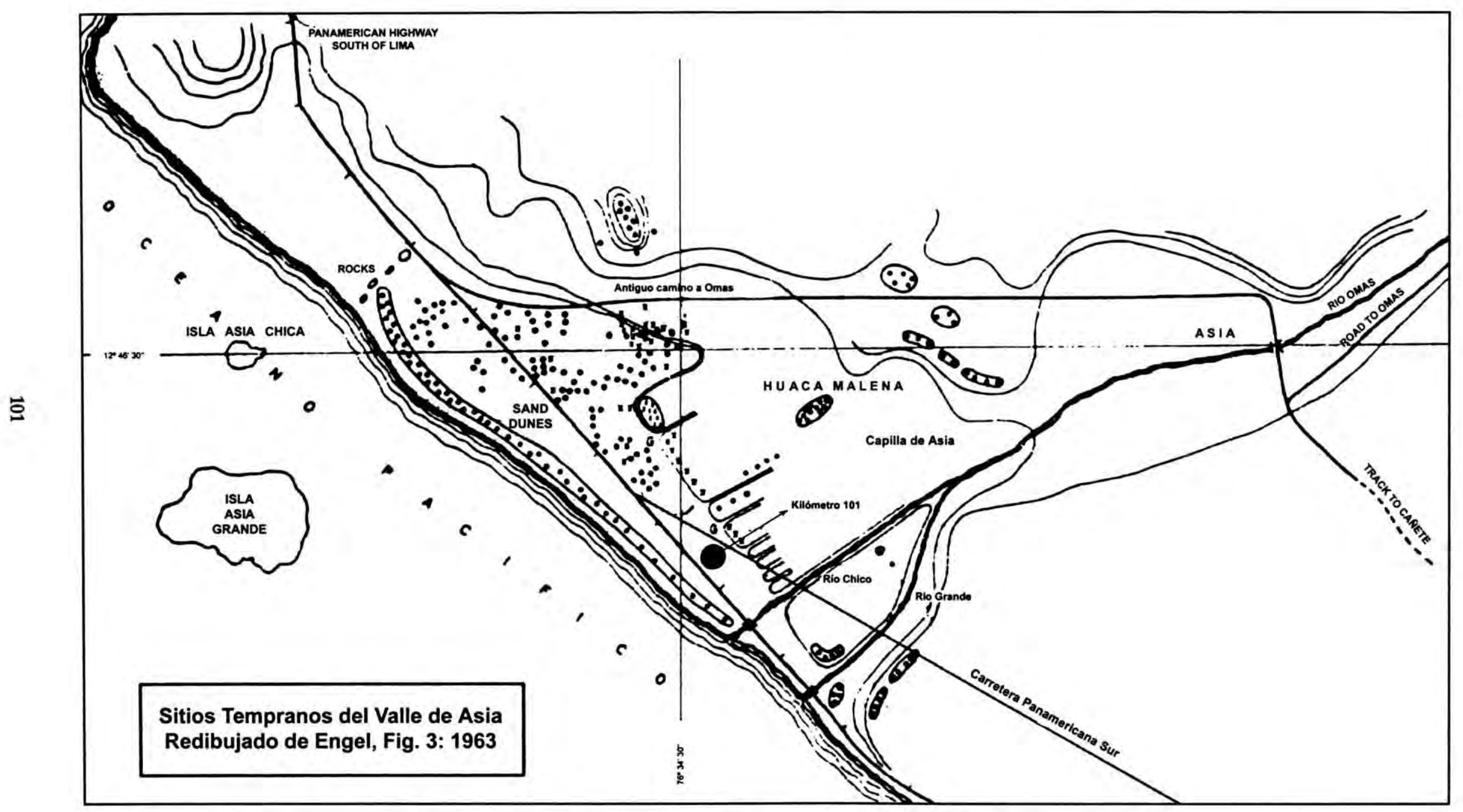

Plano 1. Sitios arqueológicos del valle de Asia, con ubicación del sitio Kilómetro 101. 
de coma. El sitio que describimos se encuentra a unos 200 metros de uno de estos últimos montículos, el cual ha sido cortado hace varios años por la construcción de la carretera Panamericana Sur (Plano 1). Estos montículos poseen una altura promedio de hasta 3 metros y un diámetro que varía entre los 5 y 10 metros. Presentan tonalidad oscura debido a la gran acumulación de material orgánico donde se distinguen moluscos, huesos, vegetales y cerámica; ésta mayormente es bruna y los bordes corresponden en su mayoría a ollas sin cuello típicas de este período. No se ha registrado la presencia de arquitectura monumental, tal como ocurre en los valles de la costa central. Engel (1966: 43) menciona la existencia de una estructura monumental ubicada en el valle bajo que le recordaba a Punkuri del valle de Nepeña; esta estructura desapareció con el avance de la agricultura en la década de los sesenta.

Durante un reconocimiento al valle medio no hemos identificado ocupaciones de este período hasta la fecha. Destaca, sin embargo, la existencia de evidencias correspondientes al Formativo Tardío con materiales relacionados al estilo Patos del valle de Cañete registrados por Wallace.
Los estudios de épocas posteriores se restringen a los sitios arqueológicos de Huaca Malena (Ángeles y Pozzi-Escot 2000; Tello 2000) que presenta una ocupación perteneciente al Intermedio Temprano y al Horizonte Medio. Una gran cantidad de asentamientos tardíos, donde destaca la presencia de plataformas de tapia y recintos de piedra y barro tales como Sequilao y Corralón, se ubican principalmente en el valle medio; algunos de ellos incluyen arquitectura de adobes de filiación Inca. Uquira (Negro 1974; Coello 1987), un importante sitio administrativo Inka, constituye el principal sitio de dicha época.

\section{EL SITIO}

Se encuentra a la altura del kilómetro 101 de la Carretera Panamericana sur, a 2 kilómetros del litoral. Al efecto lo hemos denominado KILÓMETRO 101 con fines de ubicación, debido a la gran cantidad de montículos existentes en la zona y que no poseen a la fecha una denominación particular. El área se halla al interior de una cantera de arcilla en uso actual (Foto 1), cuyos terrenos pertenecen al señor Alfredo Aburto

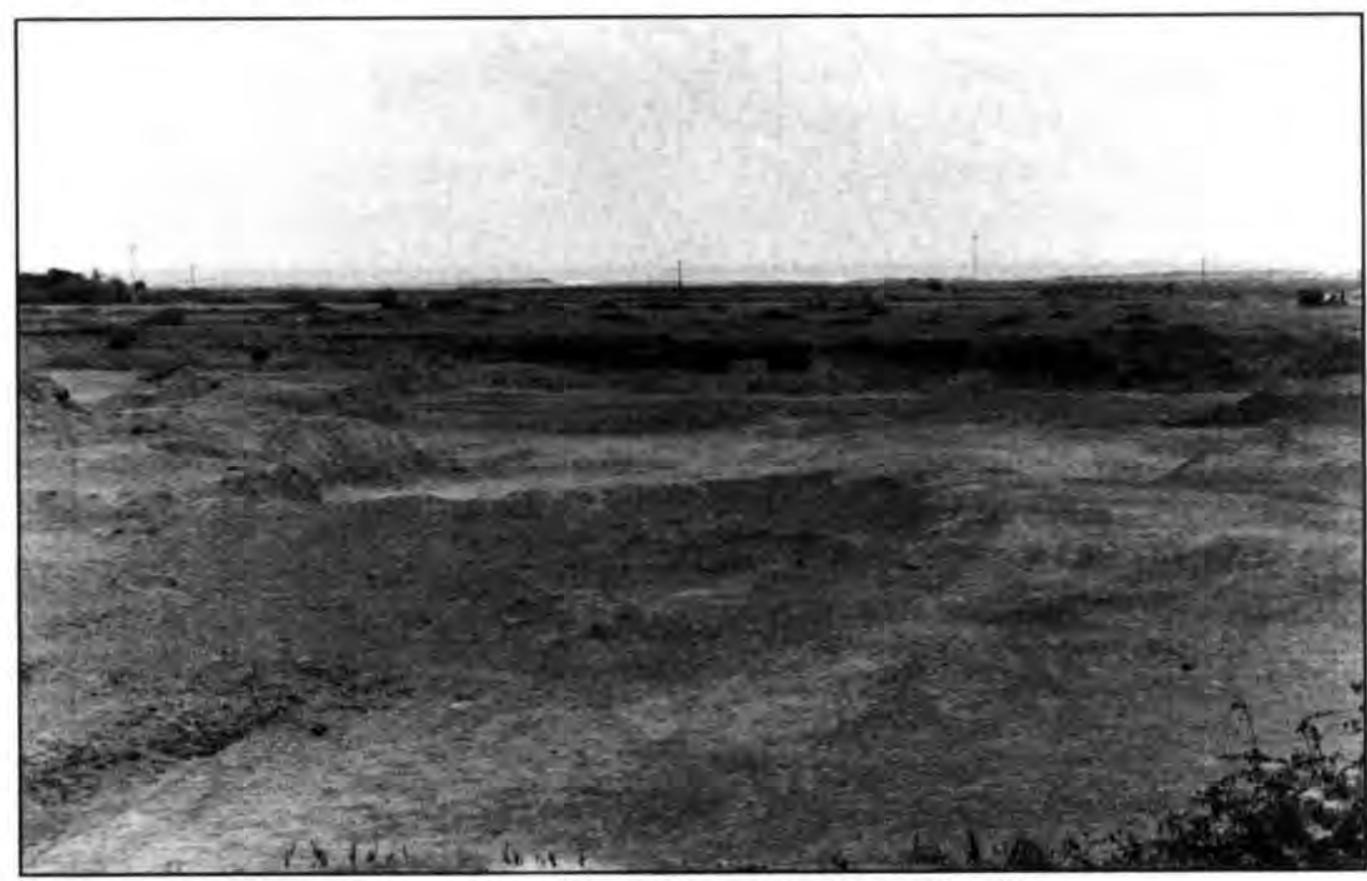

Foto I. Vista general de la cantera Kilómetro 101. 
Campos. Antiguamente era una zona de cultivo que se convirtió en cantera de tierra para ser llevada a los jardines de los clubes de playa existentes en el litoral, función que cumple hasta la fecha. En superficie no se distingue, pues, evidencia de ocupación prehispánica en la zona. Esta cantera tiene un área aproximada de 4 hectáreas. La profundidad que alcanza supera los 3 metros y en los perfiles es posible distinguir al menos tres momentos de ocupación humana representada por pisos asociados a capas de material orgánico donde destaca la presencia de moluscos.

De acuerdo a la estratigrafía, hemos podido definir tres niveles de ocupación importantes (Foto 2). El más antiguo correspondiente al Precerámico, es un piso asociado con conchas, restos orgánicos y escaso material lítico, con ausencia de cerámica, ubicado a una profundidad de 3 metros. Éste tenía una gran extensión, pues ocupa casi la totalidad de la cantera; lamentablemente esta cantera en uso desde hace unos seis años habría destruido casi la totalidad de evidencias. El piso asociado incluye huellas de quema en algunos sectores que produjo altos grados de calor, pues la superficie conserva una tonalidad rojiza. El espesor de esta capa va desde los 5 centímetros hasta los 40 centímetros. En ella destaca la presencia de material malacológico, principalmente Mesodesma donacium (macha) en alta proporción; en mucho menor grado se observa Choromytilus chorus (choro zapato) y escasos moluscos de playas rocosas, tales como Thais chocolata.

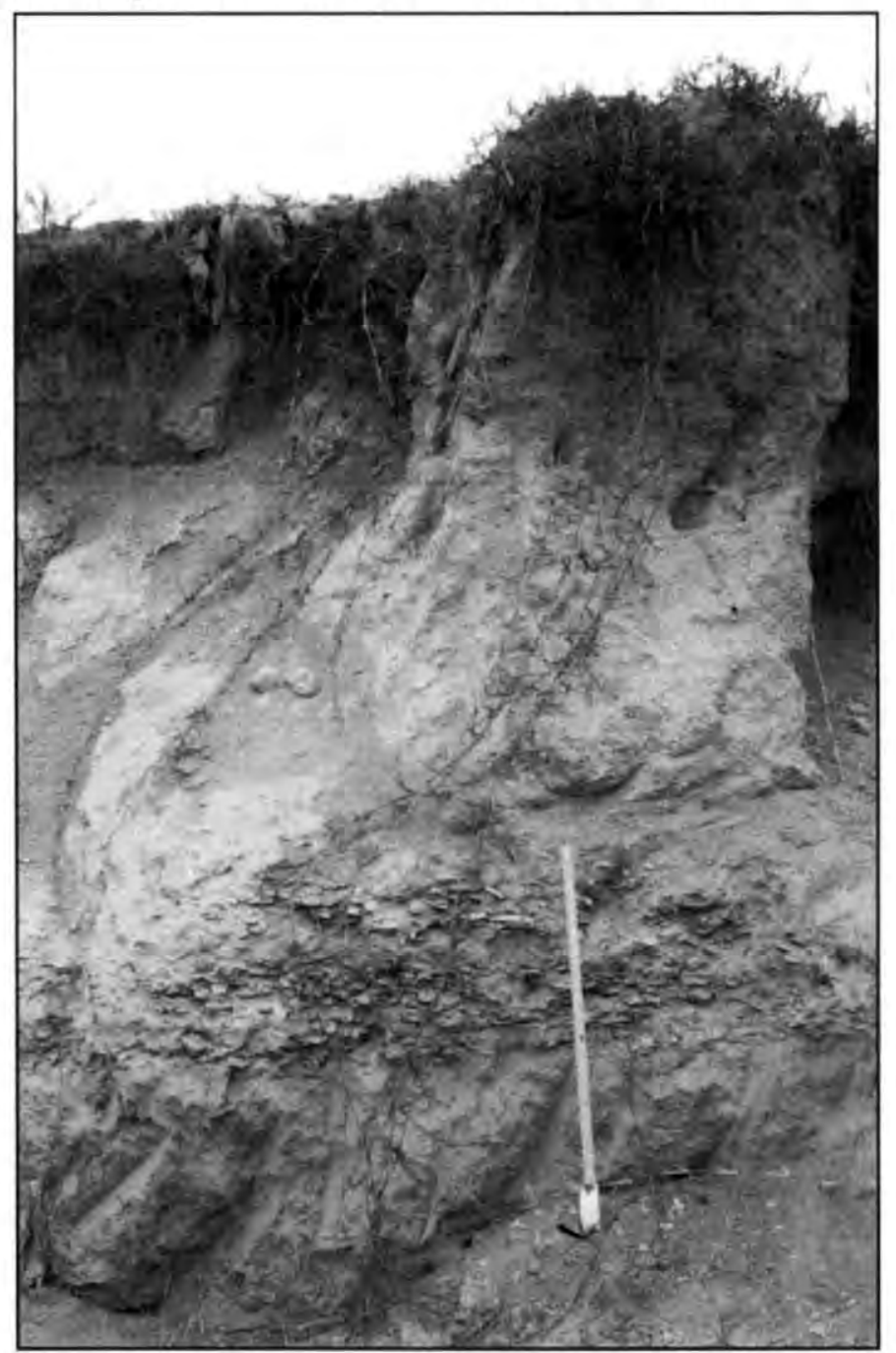

Foto 2. Detalle del perfil de la cantera Kilómetro 101. Nótese el nivel precerámico. 
El segundo nivel se halla a $2,50 \mathrm{~m}$ de profundidad y sólo se observa en algunos sectores de la cantera. En éste prevalece la presencia de conchas, con especial énfasis Mesodesma donacium, también perteneciente al Precerámico, debido a la ausencia de cerámica.

Este tercer nivel, que es el superior, se halla entre $50 \mathrm{~cm}$ y 1 metro de profundidad, y es el menos conservado debido a la explotación de la cantera. El contexto descrito en este artículo procede de ese lugar. Se trata de un nivel donde se observa un piso, poco material malacológico, escasos fragmentos de cerámica y las evidencias de la tumba disturbada que aquí mencionamos.

A 200 metros del área existe un montículo cortado por la carretera Panamericana sur, el cual presenta cerámica del Formativo correspondiente a las fases 3 y 4 de la secuencia de Ancón. El hallazgo presenta una vasija de dicho período.

Podemos indicar que el área muestra una secuencia estratigráfica desde el período Precerámico al Formativo. Estas ocupacio- nes se encuentran separadas por capas aluviales.

\section{DEL CONTEXTO}

El área presenta tierra de origen aluvial sobre la cual aparece un lente de material cultural correspondiente al Formativo (Foto 3 ).

De acuerdo a nuestro informante, que trabaja regularmente en la zona, no había visto hallazgos similares con anterioridad, a excepción de otro contexto igualmente destruido del cual recuperamos una botella con decoración incisa, completamente fragmentada, la cual fue hallada por otro grupo de trabajadores.

Es difícil determinar la presencia de evidencias de otros contextos funerarios cercanos, por lo que planteamos que el hallazgo reportado corresponde a un entierro. De acuerdo a estos datos, podemos deducir que las asociaciones de la tumba descrita pertenecen a un solo individuo. Del mismo modo, el análisis de los huesos indica que pertenecen a un solo individuo.

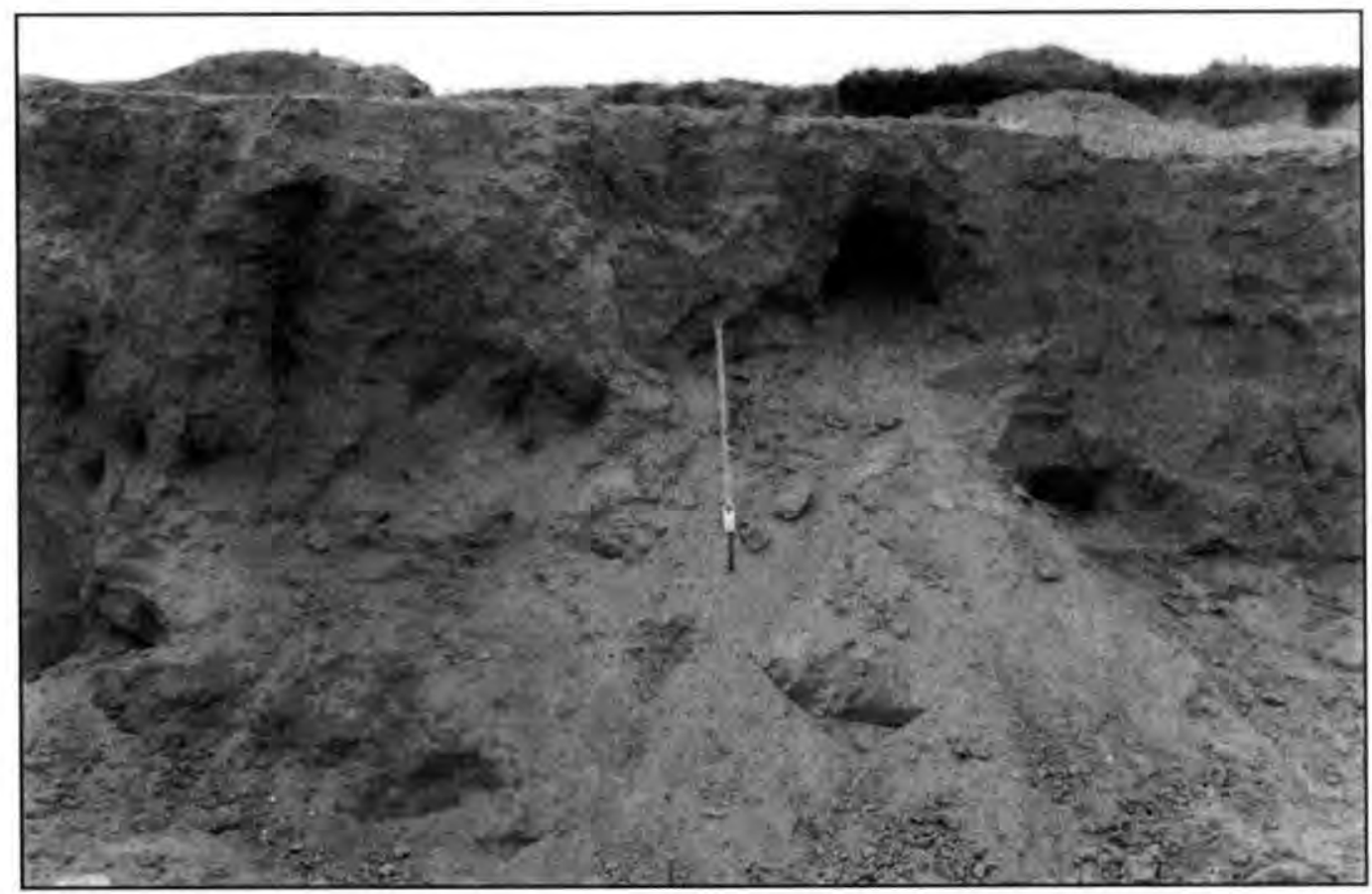

Foto 3. Kilómetro 101. Area del hallazgo. Corte del perfil de la tumba. 
El hallazgo fue realizado por el señor Carlos Malásquez Lara, natural de Rosario de Asia, quien indica que durante la extracción de tierra cayó del perfil el material en mención. Indica, asimismo, que se halló conjuntamente un artefacto de madera que fue lamentablemente destruido.

\section{DEL INDIVIDUO}

No conocemos con precisión la posición del individuo; de éste sólo se han recuperado fragmentos de la rótula, del cráneo y dos dientes. Éstos corresponden a una persona adulta de avanzada edad, resultando interesante la ausencia de huesos del cuerpo.

Los huesos se hallan quemados y sólo fueron hallados algunos de ellos. Esta situación incluso puede plantear que se trate de una ofrenda. Por la presencia de huesos quemados (coloración grisácea, otros sumamente frágiles) Lumbreras (1989:206-217) postula que este tipo de hallazgos corresponde a evidencias de prácticas de canibalismo.

\section{DE LAS ASOCIACIONES}

Como dijimos anteriormente, la zona no presenta evidencias de otros contextos funerarios cercanos, por lo que planteamos que éstos provienen de la única tumba reportada. Sin embargo, en las cercanías se ubicó otra tumba. En este caso se recuperó los restos de una botella con decoración incisa, completamente fragmentada.

No conocemos la ubicación interna de los objetos asociados. Sin embargo, destaca la variedad de objetos reportados; éstos incluyen:

2 vasijas de cerámica

10 puntas de obsidiana

1 buril de obsidiana

\section{2 lascas de obsidiana}

1 punta de doble muesca basal

1 espejo de antracita

1 espejo de piedra pulida

1 hacha de piedra pulida

8 cuentas tubulares de hueso

1 cuenta tubular de concha

1 fragmento de inhalador

6 fragmentos de una tableta de rapé

Huesos cortados

1 fragmento de una sonaja escultórica de hueso

1 escultura de hueso

1 disco de cobre

A ello se suman los fragmentos de huesos humanos. Pasaremos a describir cada uno de los objetos.

\section{Cerámica}

Dos vasijas estuvieron asociadas al individuo (Foto 4). De éstas se recuperaron fragmentos de una botella globular de cuello largo con borde biselado, color negro bruno y superficie con pulido bajo. No presenta decoración y su construcción utilizó el sistema de enrollado. Ésta es una botella de cuerpo compuesto, cuello recto y cuerpo globular. La boca tiene un ancho de $5 \mathrm{~cm}$, el cuello tiene un largo de $7,5 \mathrm{~cm}$ con un ancho de $5 \mathrm{~cm}$. La base es plana.

La pasta es de color crema grisáceo, de grano fino, y presenta inclusiones negras correspondientes a material orgánico (pequeños tallos).

La segunda vasija corresponde a un bol llano de color negro de $8 \mathrm{~cm}$ de altura y $8 \mathrm{~cm}$ de ancho.

La botella recuerda en forma a botellas de estilo Ofrendas de Chavín de Huántar (Lumbreras, comunicación personal) y presenta rasgos de otras botellas descritas para la tra- 


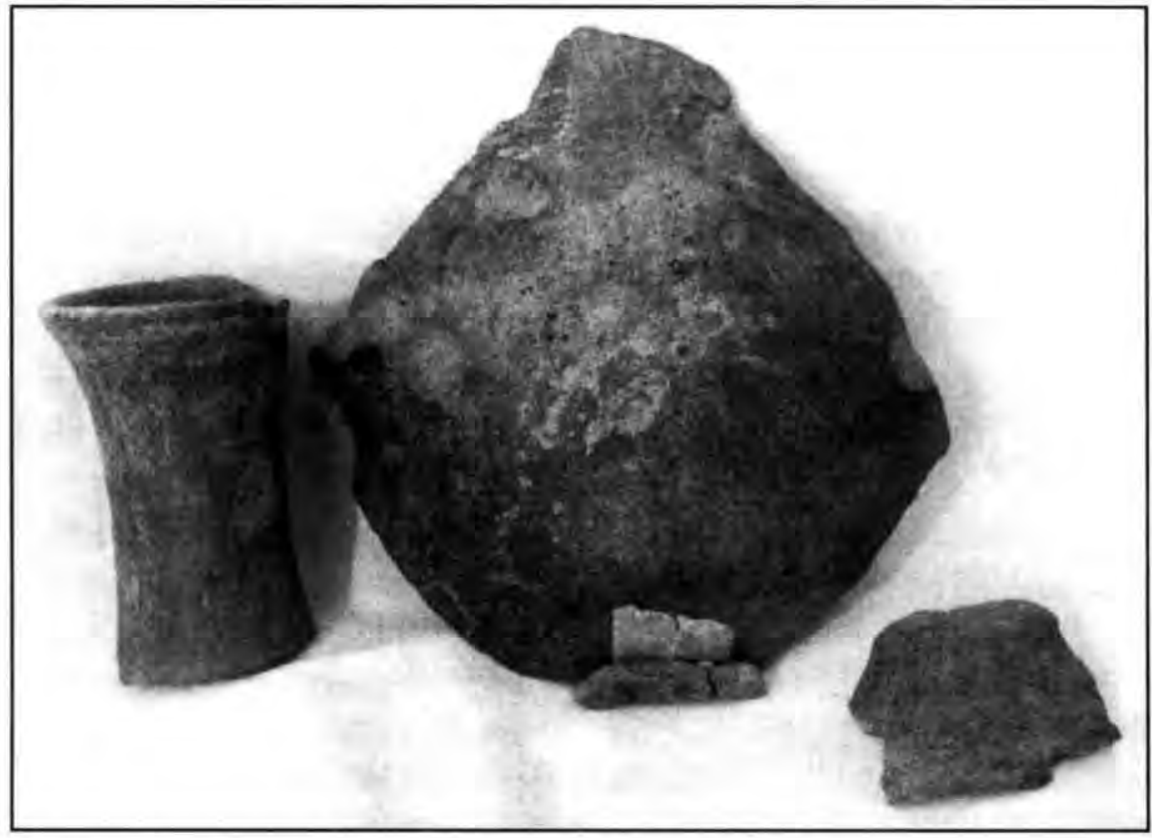

Foto 4. Cerámica asociada a la tumba.

dición de Ancón de la costa central y Chavín de Huántar, relacionado a la fase Ofrendas dentro del estilo "Dragoniano" (véase: Lumbreras 1989 fig. 64) que a su vez incluye un alfar marrón (op. cit. p. 189).

De acuerdo a dicha descripción, se trata de botellas de gollete alargado y perfil inflexo, así como cuencos bajos, asociados a la costa de Lima en sitios como Huacoy, Garagay y Cardal.

Vasijas con decoración similar han sido reportadas por Scheelle (1970) para el valle de Lurín.

De acuerdo a Jonathan Palacios (comunicación personal) la botella tiene rasgos del estilo Ofrendas y estaría relacionada a las fases 3 y 4 de la tradición Ancón de Hermilio Rosas (Rosas: 1970).

Similar opinión corresponde a Richard Burger, quien indica que la botella corresponde a tradiciones de la costa central reportadas en Ancón.

De un segundo contexto recuperado en la zona, destaca la presencia de una botella de labio biselado, cuello recto y cuerpo globular. La parte media superior del cuerpo presenta el diseño de una boca en posición de perfil con colmillos sobresalientes (Foto $5)$.

Este tipo de iconografía es típico de la costa central.

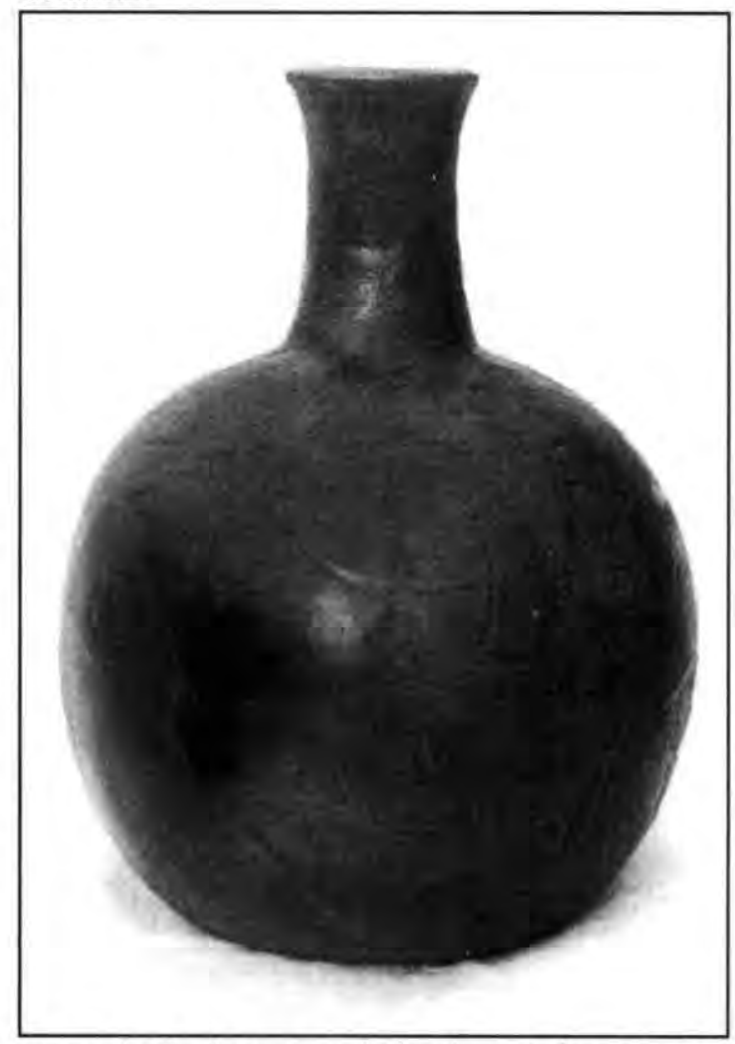

Foto 5. Cerámica asociada al segundo contexto. 


\section{Puntas de obsidiana}

Se trata de un lote de 10 puntas de obsidiana (Foto 6; Figuras 1, 2 y 3 ) que estaban asociadas a esta tumba; desconocemos si había otras más. Sin embargo, existe una característica en ellas: 8 de ellas forman pares en forma y dimensiones relativamente similares, las dos restantes son de diferente tamaño, por lo que creemos que existirían dos puntas más aún no identificadas. Todas ellas son bifaciales.

A continuación describiremos dicho material:
Las puntas presentan morfología laminar; son generalmente largas y delgadas, altamente retocadas. Soporte seudo laminar y laminar. Núcleos laminares. Han sido trabajadas usando percutor blando; presentan, asimismo, retoque plano e irregular.

De acuerdo a Elmo León, para fabricar las puntas de obsidiana siguieron estos pasos, al parecer: primero hicieron un esbozo con un percutor blando, o hasta dos, pues se observa que podrían haber sido de diferente peso y forma. Hay golpes bien al borde, de delineación irregular. También un patrón de retoque plano, irregular, pero que tiende a

\begin{tabular}{|r|r|r|l|}
\hline Ejemplar & Altura & Ancho de la base & \multicolumn{1}{|c|}{ Color } \\
\hline 1 & $65 \mathrm{~mm}$ & $17 \mathrm{~mm}$ & Marrón transparente \\
\hline 2 & $62 \mathrm{~mm}$ & $18 \mathrm{~mm}$ & Marrón transparente \\
\hline 3 & $52 \mathrm{~mm}$ & $23 \mathrm{~mm}$ & Negro con bandas diagonales \\
\hline 4 & $50 \mathrm{~mm}$ & $18 \mathrm{~mm}$ & Marrón transparente opaco \\
\hline 5 & $58 \mathrm{~mm}$ & $20 \mathrm{~mm}$ & Marrón transparente opaco \\
\hline 6 & $52 \mathrm{~mm}$ & $17 \mathrm{~mm}$ & Marrón transparente \\
\hline 7 & $32 \mathrm{~mm}$ & $8 \mathrm{~mm}$ & Negro opaco \\
\hline 8 & $32 \mathrm{~mm}$ & $15 \mathrm{~mm}$ & Marrón con bandas diagonales \\
\hline 9 & $36 \mathrm{~mm}$ & $13 \mathrm{~mm}$ & Negro con bandas diagonales \\
\hline 10 & $50 \mathrm{~mm}$ & $14 \mathrm{~mm}$ & Marrón transparente opaco \\
\hline
\end{tabular}

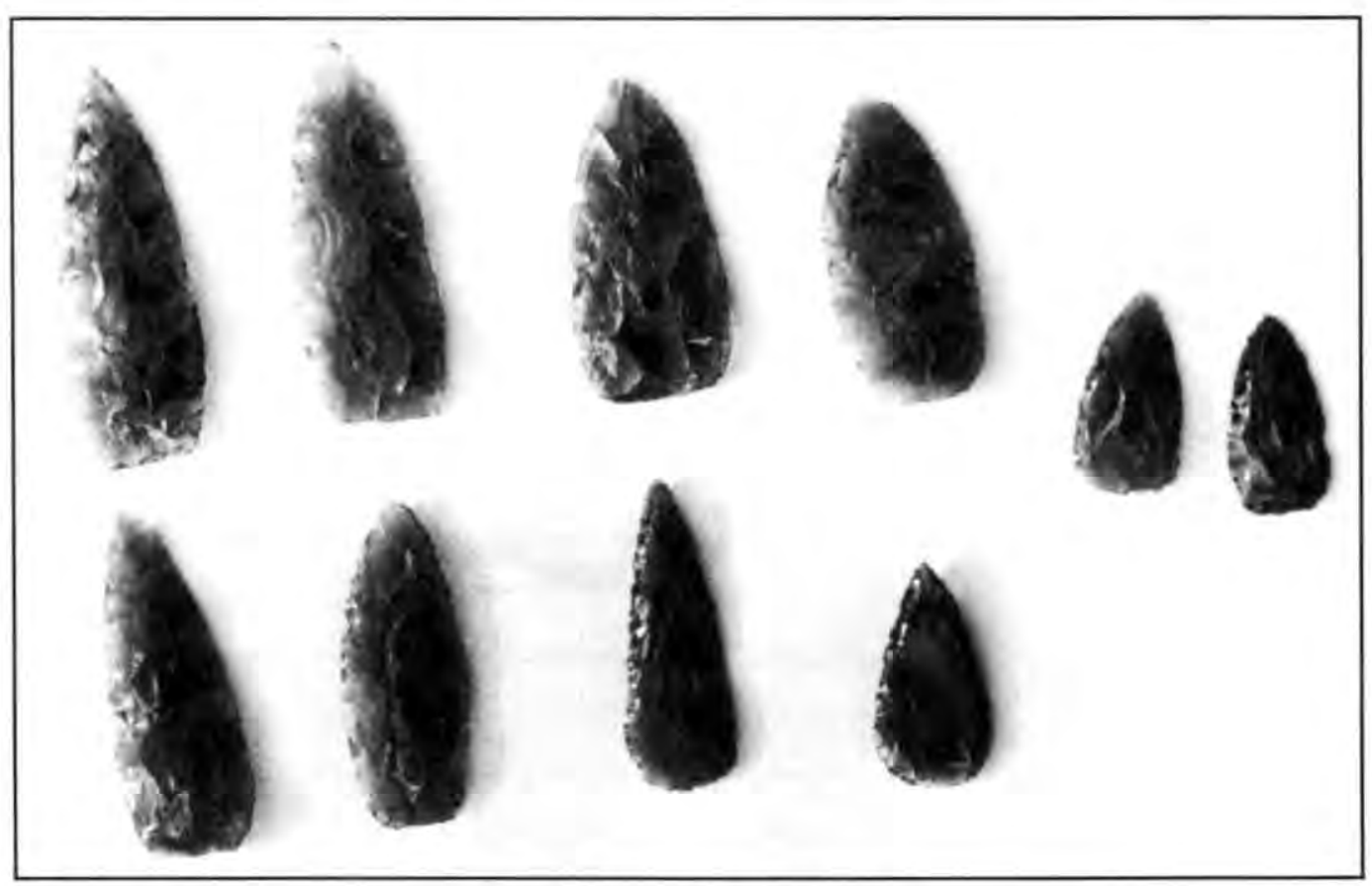

Foto 6. Puntas de obsidiana. 


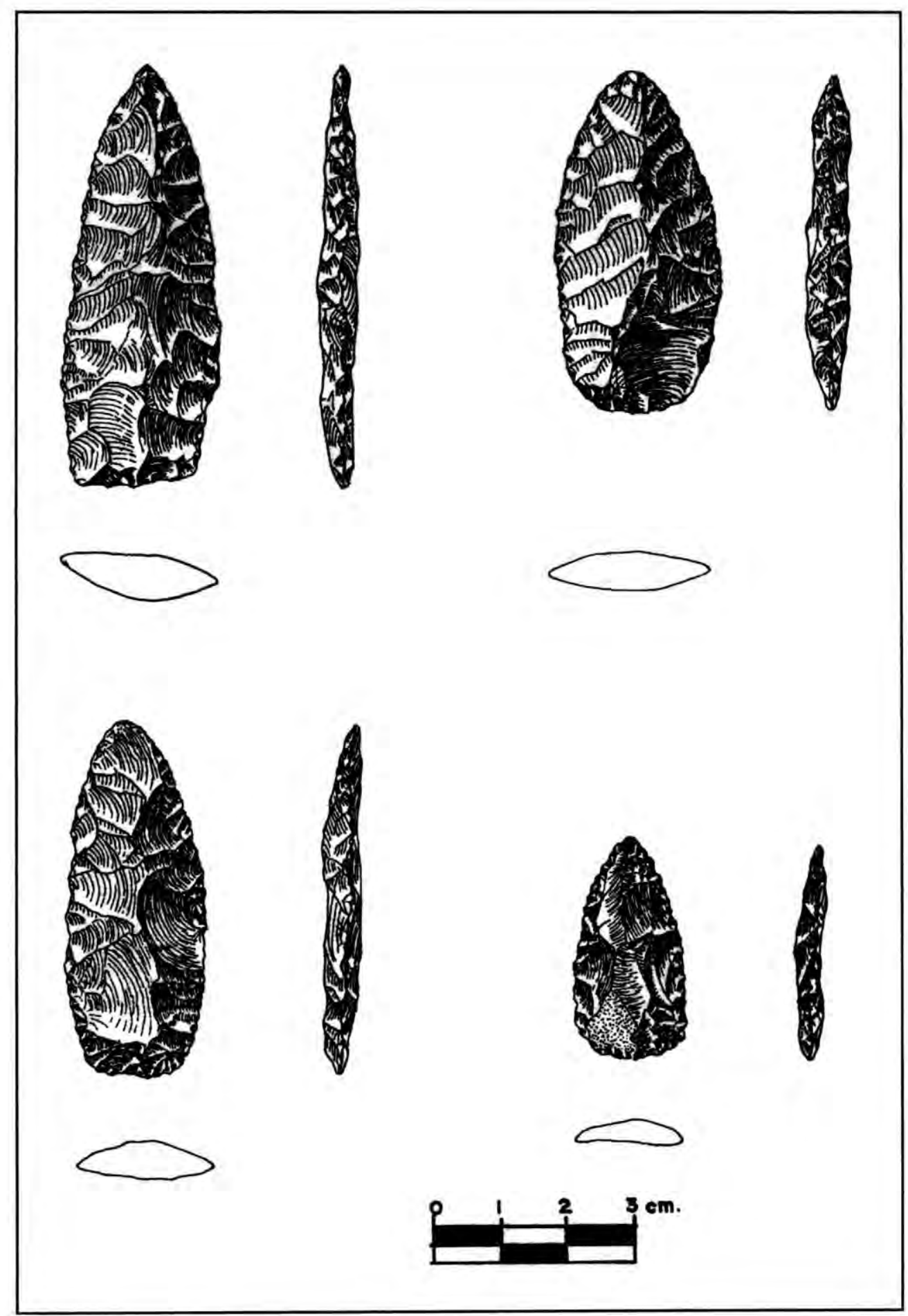

Figura I. Puntas de obsidiana. 


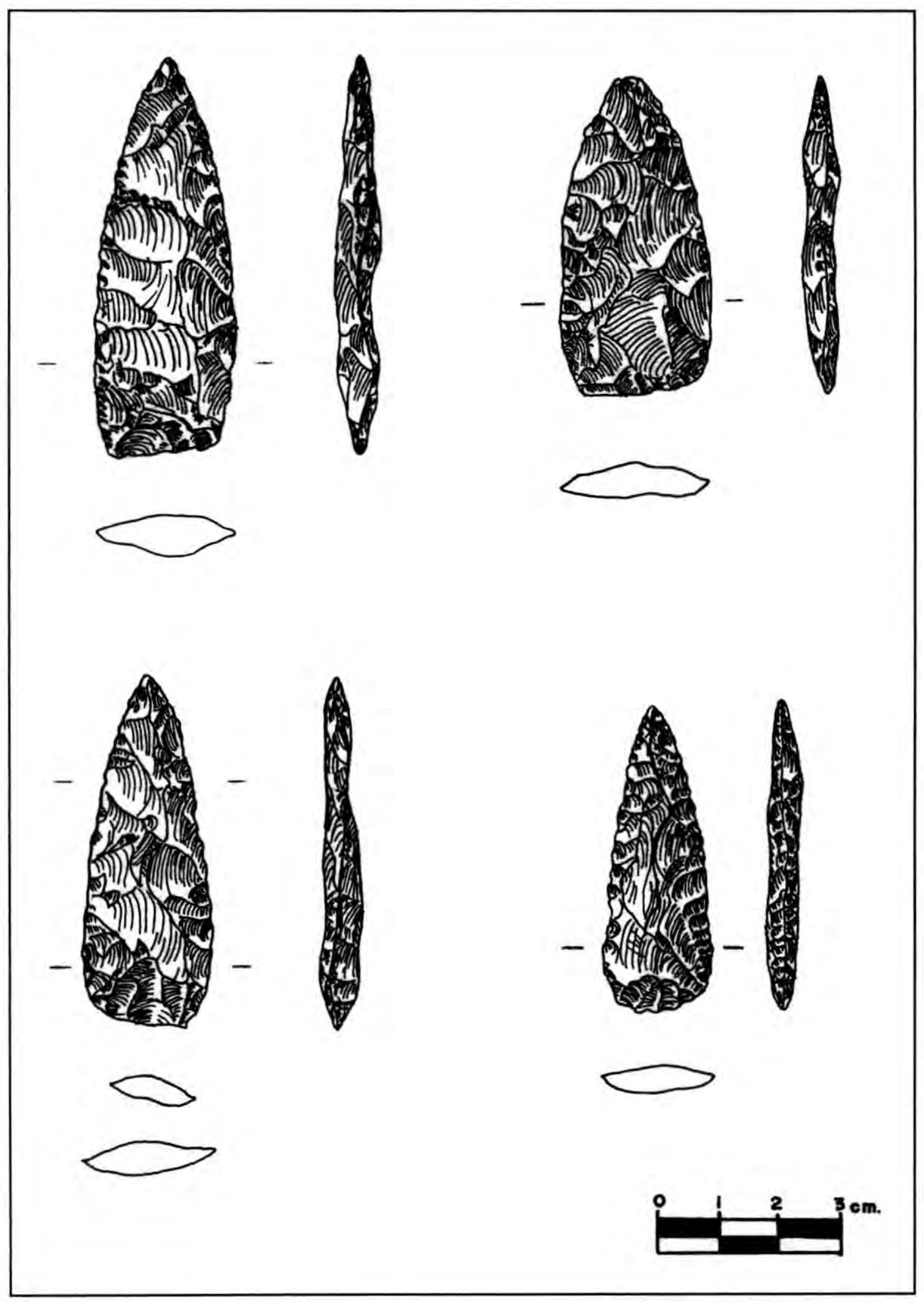

Figura 2. Puntas de obsidiana. 


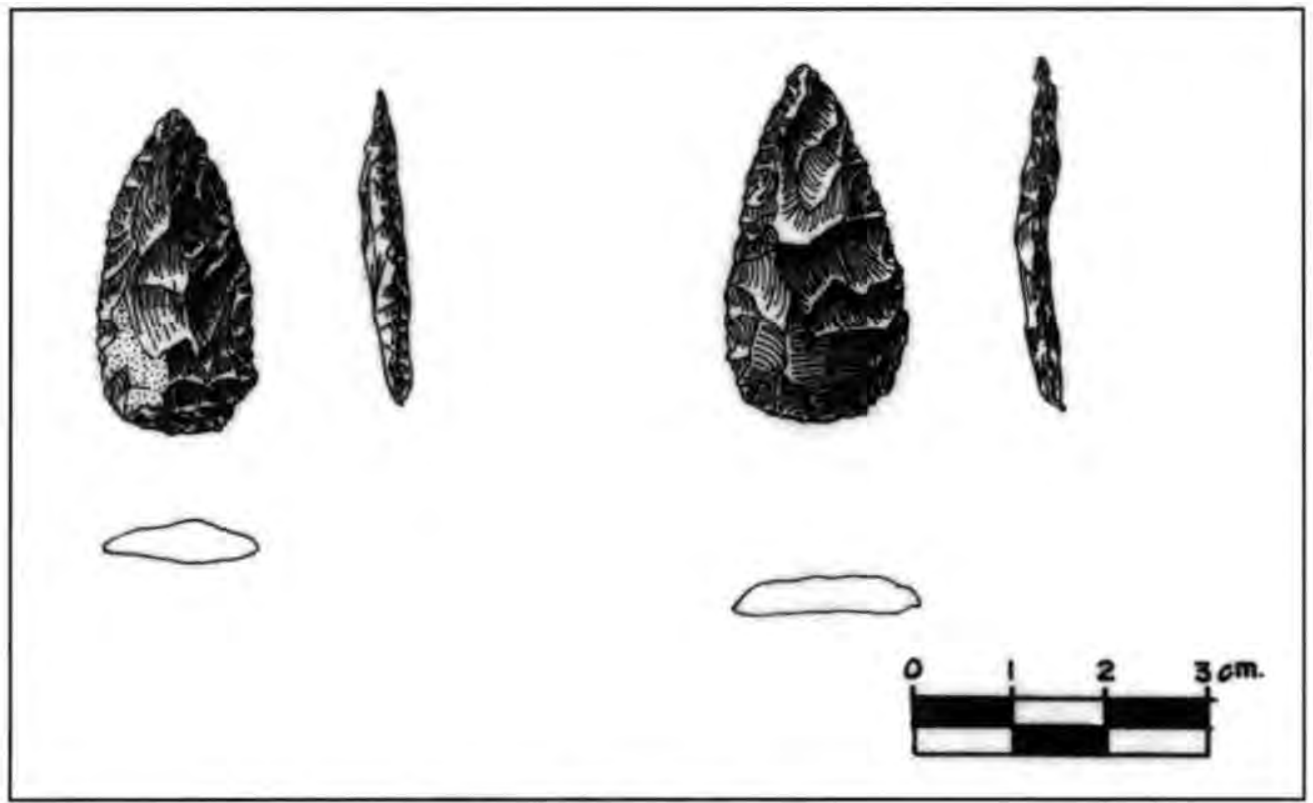

Figura 3. Puntas de obsidiana.

conservar la silueta de la pieza, sin mucho control (al parecer realizada por gente experta), hecho de forma rápida y con golpes que no son muy cuidadosos. No hay presión; en algunos bordes hay fragmentos de muescas irregulares y espaciadas: se trata de fracturas producidas por el golpe original.

Se trata de puntas trabajadas en técnica laminar, de producción en serie de láminas para hacer soportes de puntas de obsidiana; algunas han sido hechas en lascas secundarias pequeñas, piezas cuyos soportes laminares relativamente anchos son posteriormente tallados.

$\mathrm{Al}$ parecer les interesa más la forma (silueta) de la pieza; no les interesa el acabado. En este sentido presentan fallas en su construcción. Las formas en general son foliáceas con tendencia laminar y triangular alargada. Las puntas no evidencian desgaste. Si bien existe variación en la tonalidad, ello no sería indicativo de que proceden de diferentes canteras, ya que éstas varían en tonalidad dentro de un mismo núcleo (comunicación personal Richard Burger). Finalmente, estas puntas recuerdan a la tradición Paracas desde el punto de vista tecnológico, por ser bifaciales.

\section{Lascas y denticulado de obsidiana}

Se trata de dos lascas secundarias procedentes de la fase preparatoria de los núcleos. Corresponden a lascas obtenidas por el golpe de núcleo a través del proceso del desbastado. Éstas miden $22 \mathrm{~mm}$ por $11 \mathrm{~mm}$ y $30 \mathrm{~mm}$ por $22 \mathrm{~mm}$.

El denticulado es atípico (Figura 4) y hecho sobre una lasca secundaria; en las muescas hay un trabajo de presión.

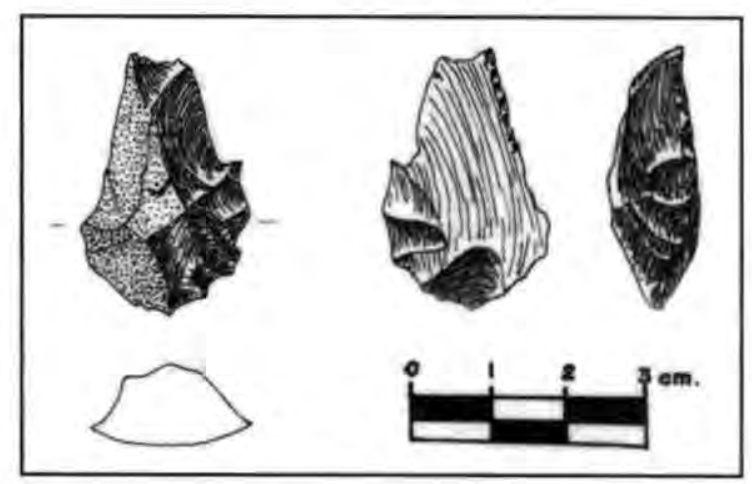

Figura 4. Denticulado de obsidiana.

El soporte es una lasca secundaria bastante ancha y pequeña cuyo bulbo ha sido reducido por tres golpes. $\mathrm{Al}$ parecer se trata de la base de un núcleo. Mide $34 \mathrm{~mm}$ por $22 \mathrm{~mm}$. 


\section{Punta de doble muesca basal}

Dentro del hallazgo destaca una excepcional punta de proyectil de doble muesca basal en los lados laterales (Figura 5, Fotos 7 y 8). Ésta tiene una altura de $108 \mathrm{~mm}$ con un ancho máximo de $45 \mathrm{~mm}$, en la segunda muesca tiene un ancho máximo de $38 \mathrm{~mm}$. Es de piedra calcedonia. Presenta retoque en los bordes. Las caras se presentan alisadas, lo que indicaría que es de naturaleza metamórfica y el soporte se presentaba altamente holitizado al ser usado para el trabajo de transformación.

Se trata de una pieza tallada mediante percusión blanda y elemental con pocos golpes. Luego de la percusión blanda se intentó trabajar el borde de la pieza por presión,

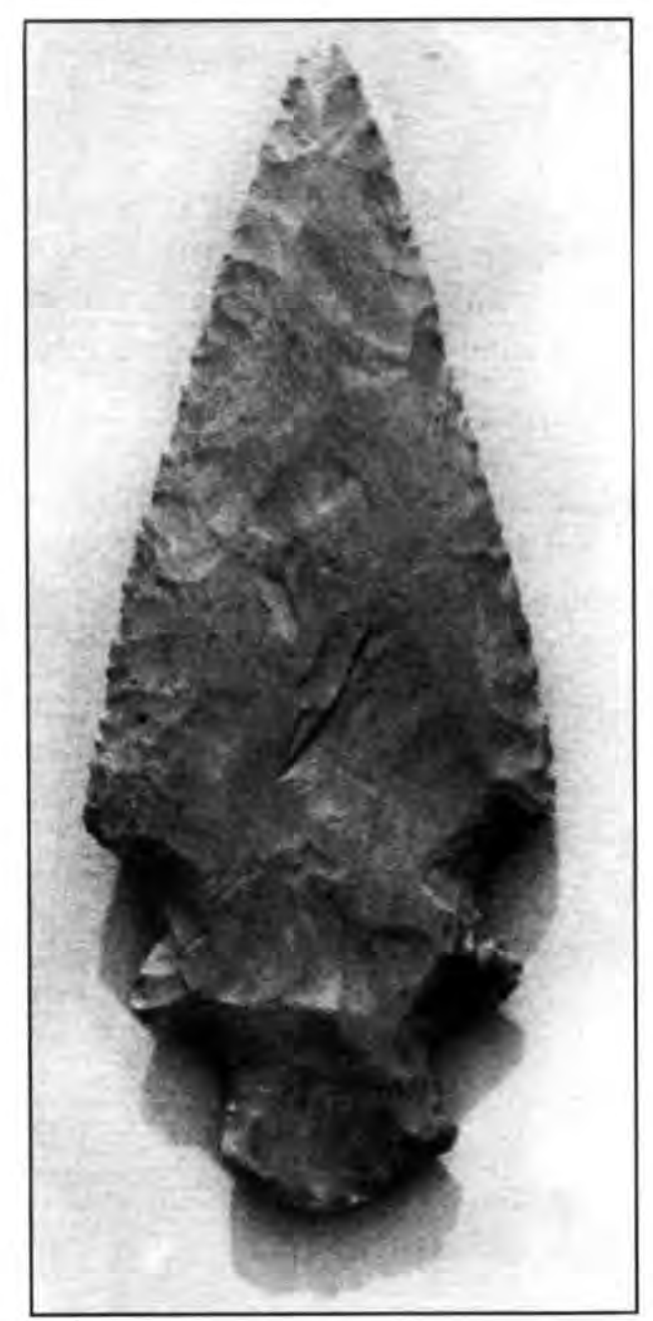

Foto 7. Punta de doble muesca basal. de forma continua, abrupta y extensiva regularizando el borde. Se trata de una pieza con trabajo bifacial.

Presenta dos muescas basales, la primera de ellas presenta un golpe bien bajo y luego retocaron el borde para regularizar la silueta; la segunda muesca basal es igual. La base es fina con presión regular bifacial. La pieza indica un buen trabajo de retoque.

La forma de esta punta es poco común. Ruth Shady nos comentó el hallazgo de un fragmento de estas puntas durante la prospección en el valle de Supe. Un ejemplar completo de similares características procedente de Kotosh se encuentra en el depósito de material lítico del Museo Nacional de Arqueología, Antropología e Historia.

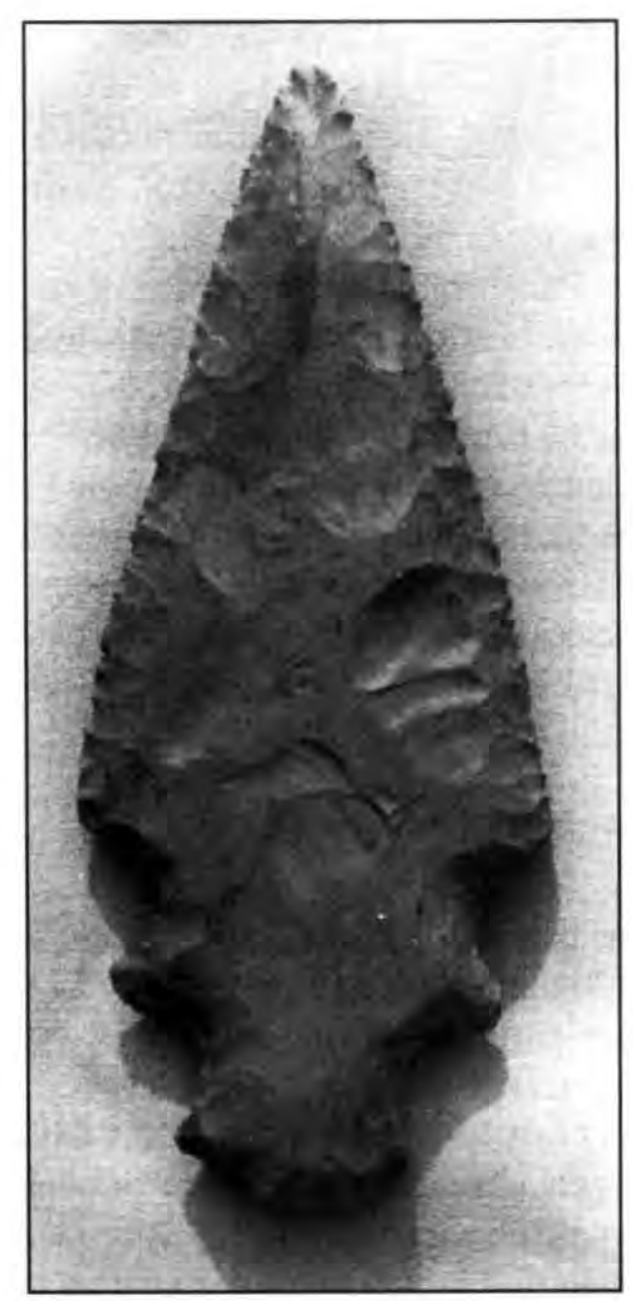

Foto 8. Punta de doble muesca basal. 


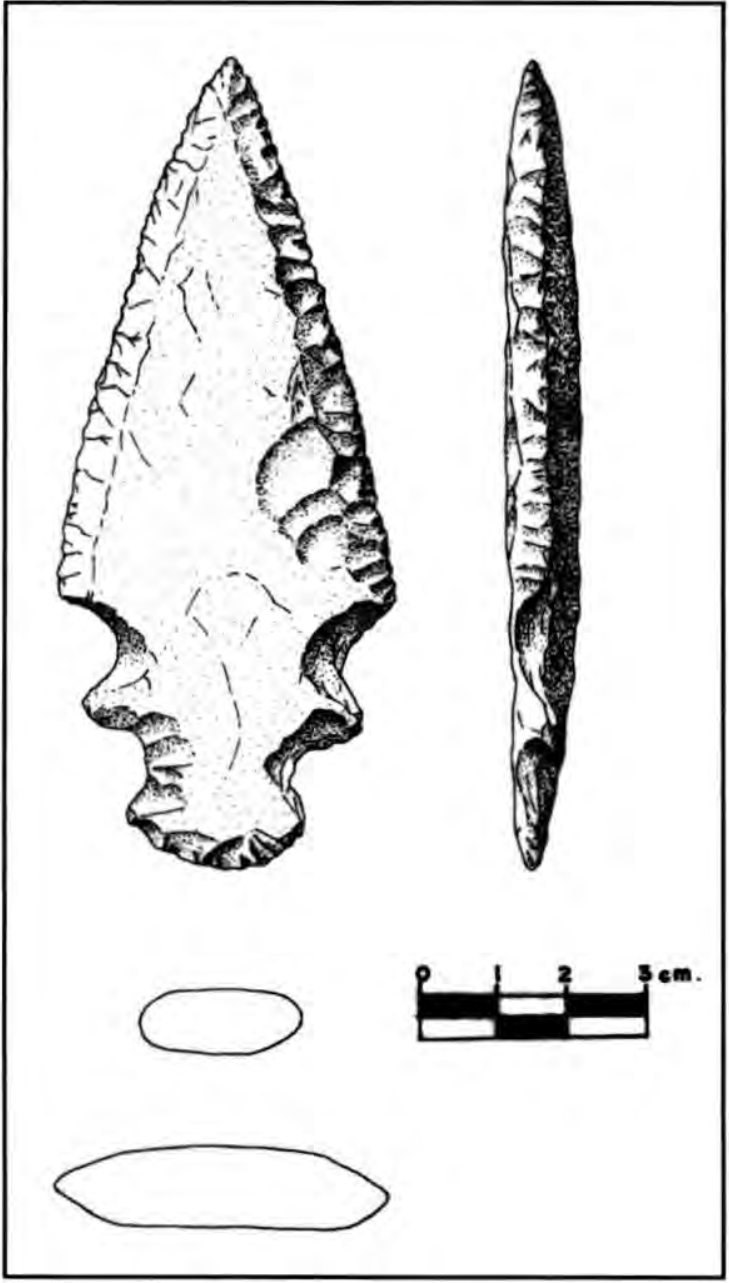

Figura 5. Punta de doble muesca basal.

Richard Burger considera igualmente que esta punta es atípica y la primera que él observa en los Andes Centrales; sin embargo, indicó que puntas de esta forma son muy comunes en contextos Maya, pero para un uso ceremonial.

\section{Espejo de antracita}

Un espejo de antracita de $77 \mathrm{~mm}$ de largo por $70 \mathrm{~mm}$ de alto y un espesor de $13 \mathrm{~mm}$, forma parte del mismo lote. Es de forma rectangular con las esquinas ovaladas.

Presenta una cara pulida de manera uniforme, pero con acabado mate. La otra cara no ha sido pulida aunque se presenta un corte parejo (Foto 9).

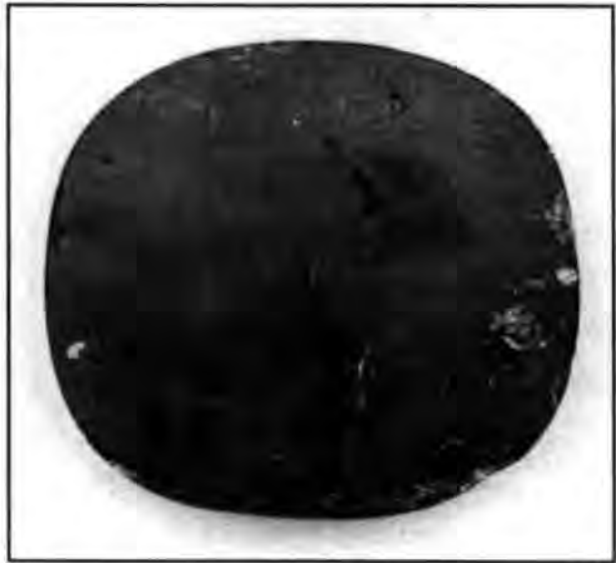

Foto 9. Espejo de antracita.

Fue fabricada cortando por la mitad una roca de antracita redonda, la cual fue cortada en dos; la parte correspondiente a la cara ha sido sumamente pulida. La otra cara presenta un pulimento menor.

Estos indicadores plantearían un buen trabajo de limado de dicha superficie.

Espejos de antracita han sido reportados para Ancón y principalmente en la zona de Cupisnique. Richard Burger nos comunica que las formas rectangular y circular son relativamente comunes en los basurales de Ancón.

El entierro LVIII de las excavaciones de Carlos Elera en el sitio arqueológico de Puémape, incluye un espejo de similar forma pero sumamente pulido (Museo de la Nación).

\section{Espejo de piedra pulida}

Un espejo confeccionado a partir de un canto rodado seleccionado. Está finamente pulido con una cara lisa y de contorno irregular (Fotos 10 y 11).

Presenta una tonalidad jaspeada a manera de ágata, en tonalidad ocre y parda. Ha sido cortada por la mitad y presenta dos caras pulidas, una de ellas con mayor brillo. 
Medidas: $65 \mathrm{~mm} \times 45 \mathrm{~mm}$ con un espesor de $16 \mathrm{~mm}$.

$\mathrm{Al}$ igual que el espejo de antracita, éste presenta el mismo tipo de corte en ambas caras, siendo una de ellas la más pulimentada.

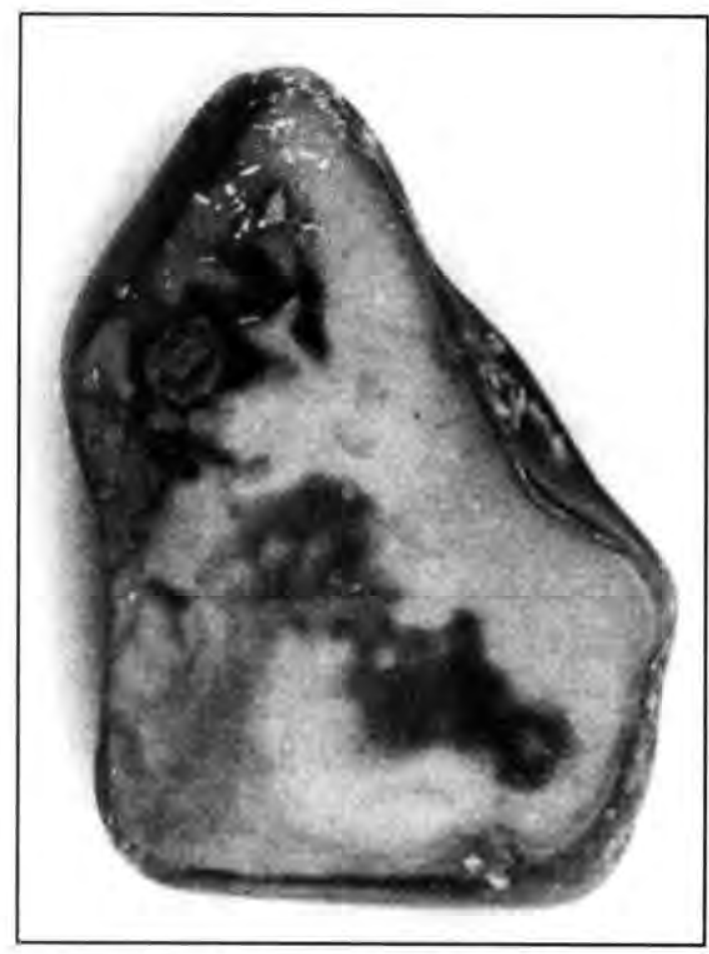

Foto 10. Espejo de piedra pulida.

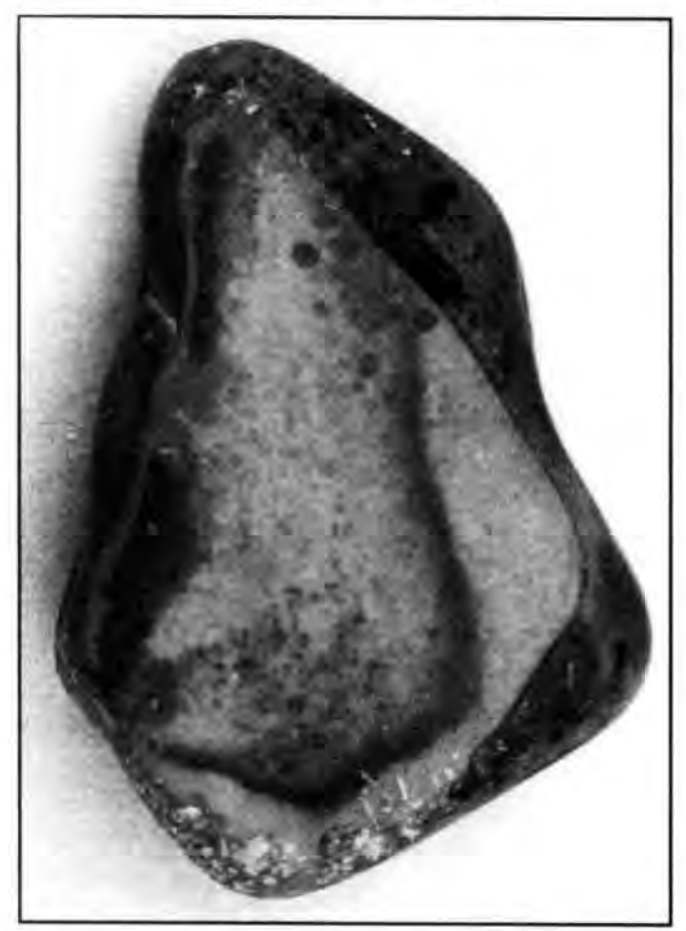

Foto 11. Espejo de piedra pulida.

\section{Hacha de piedra pulida}

Un instrumento de piedra pulida y cortada de forma pentaloide es otro elemento asociado a la tumba (Figura 6).

Mide $85 \mathrm{~mm}$ de altura, con un ancho en la parte superior de $52 \mathrm{~mm}$. La altura de los hombros (pecíolos) es de $25 \mathrm{~mm}$. El cuello tiene $42 \mathrm{~mm}$ y la parte inferior posee un ancho máximo de $72 \mathrm{~mm}$. Presenta cinabrio en los lados laterales.

De acuerdo a Richard Burger, éstos han sido definidos como instrumentos para la agricultura, y un ejemplar muy desgastado procede de un contexto del período Inicial en Kotosh (Burger 1992: Fig. 116). Otros ejemplares sin contexto definido proceden de la zona del Alto Huallaga.

Julio C. Tello (1960: 306, Figs. 138 b y 139 a, b, c) las denomina "hachas" y las describe como procedentes de contextos no definidos del templo de Chavín de Huántar. Al parecer este material apareció disturbado con cerámica Chavín, Recuay y Marañón, así como existen en Paracas y Ancón. Las "hachas" descritas por Tello son fragmentos, a excepción de la figura 138 b la cual mide $60 \mathrm{~mm}$ de longitud, $66 \mathrm{~mm}$ de diámetro mayor y $24 \mathrm{~mm}$ de diámetro menor. Los pecíolos miden $23 \mathrm{~mm}$; ésta presenta una ranura en la parte media superior.

El ejemplar de Asia parece por el contrario que había cumplido una función ritual, ya que no evidencia desgaste en el cuerpo y presenta huellas de cinabrio en los lados laterales.

\section{Cuentas tubulares de hueso}

Ocho cuentas tubulares de hueso, un fragmento de cuenta y una cuenta tubular de concha formaron parte del hallazgo. 


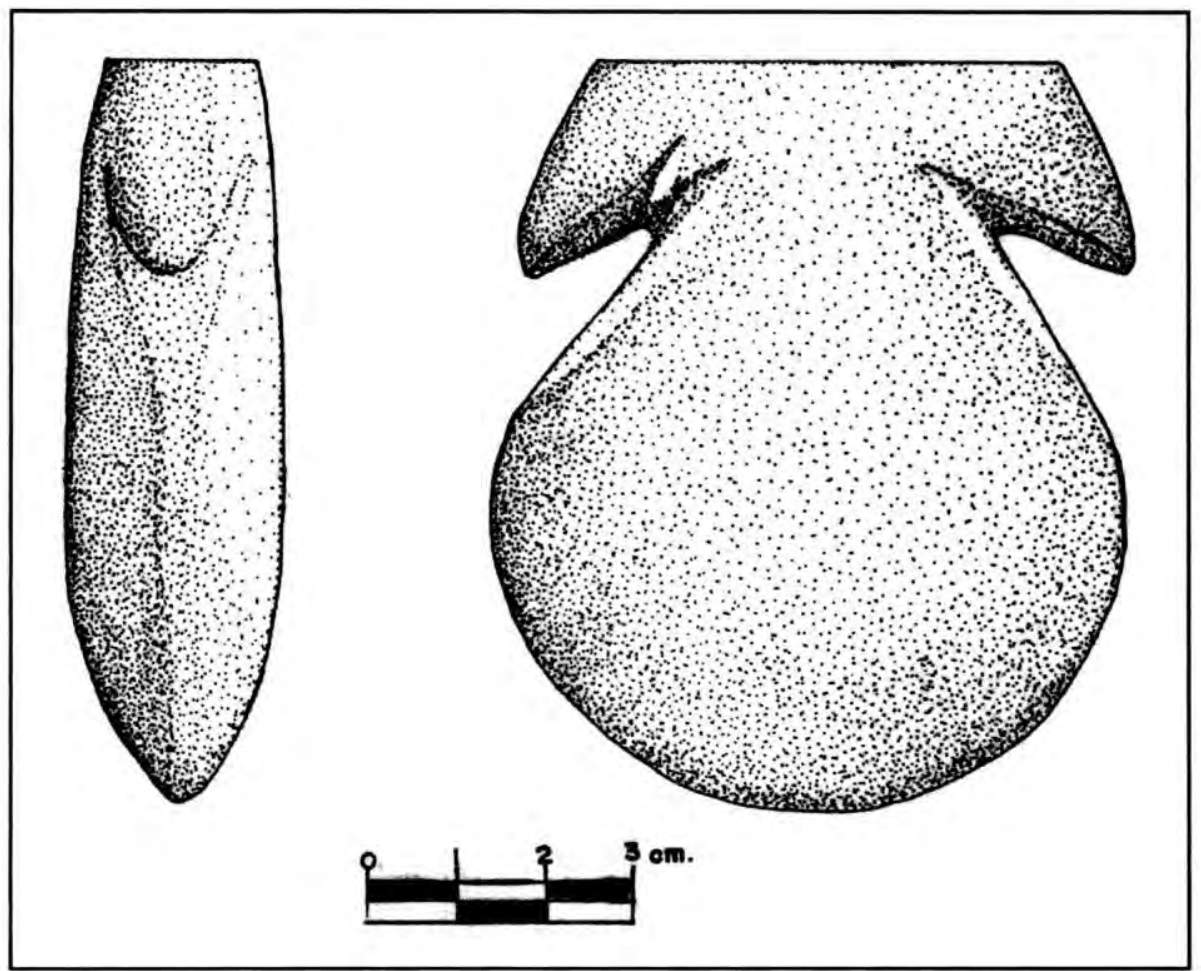

Figura 6. Hacha de piedra pulida.

Las cuentas de hueso tienen dos medidas regulares: $26 \mathrm{~mm}$ de alto $\times 10 \mathrm{~mm}$ de ancho y $20 \mathrm{~mm}$ de alto $x 10 \mathrm{~mm}$ de ancho, es decir que pertenecen a un mismo tipo de hueso y los cortes son regulares.
La cuenta de concha pertenece a una Oliva $s p$. y mide $15 \mathrm{~mm}$ de largo por $8 \mathrm{~mm}$ de espesor (Foto 12).

Éstas debieron formar parte de un collar.

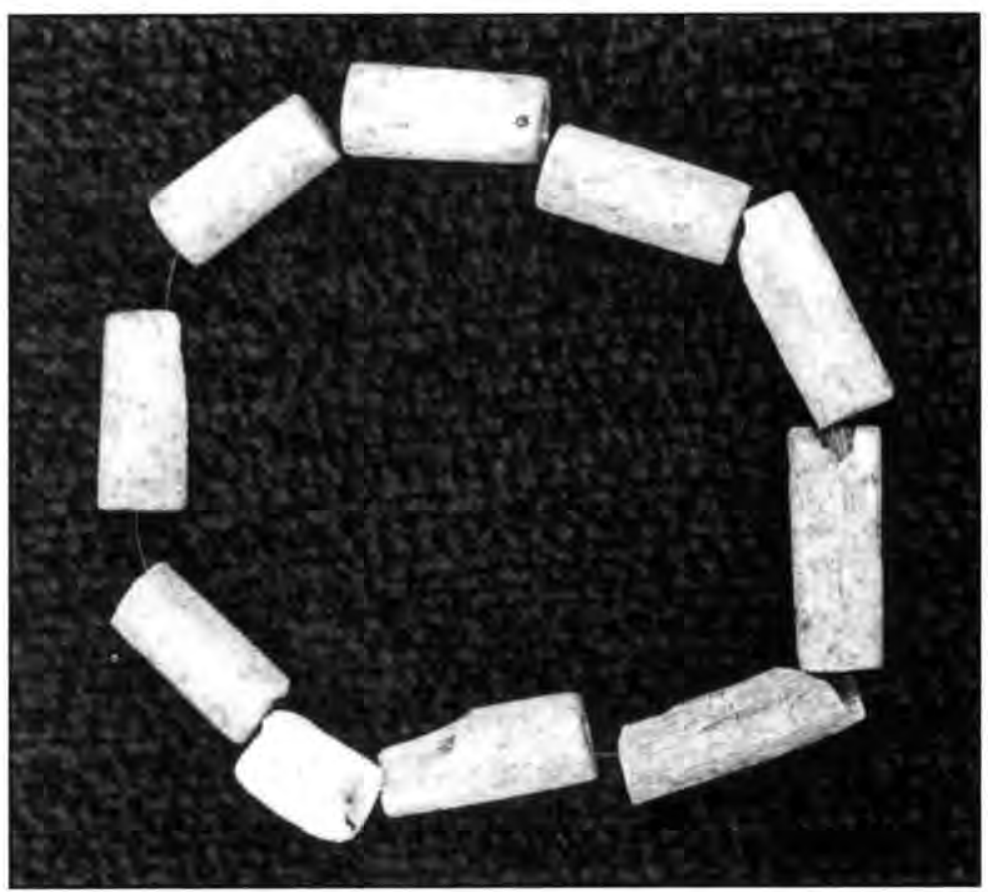

Foto 12. Cuentas tubulares de hueso. 


\section{Fragmento de cuchara de hueso}

Un instrumento fabricado de un hueso largo de animal, que corresponde al cuerpo de una cuchara que debió ser utilizada como inhalador. Está sumamente pulido (Figura 7) y recuerda por su forma a la sección media de la cuchara de un inhalador de oro procedente de la Colección Dalmau de Trujillo que forma parte de la colección de Dumbarton Oaks (1996, plate 3), publicado igualmente por Burger (1992: Fig. 85)

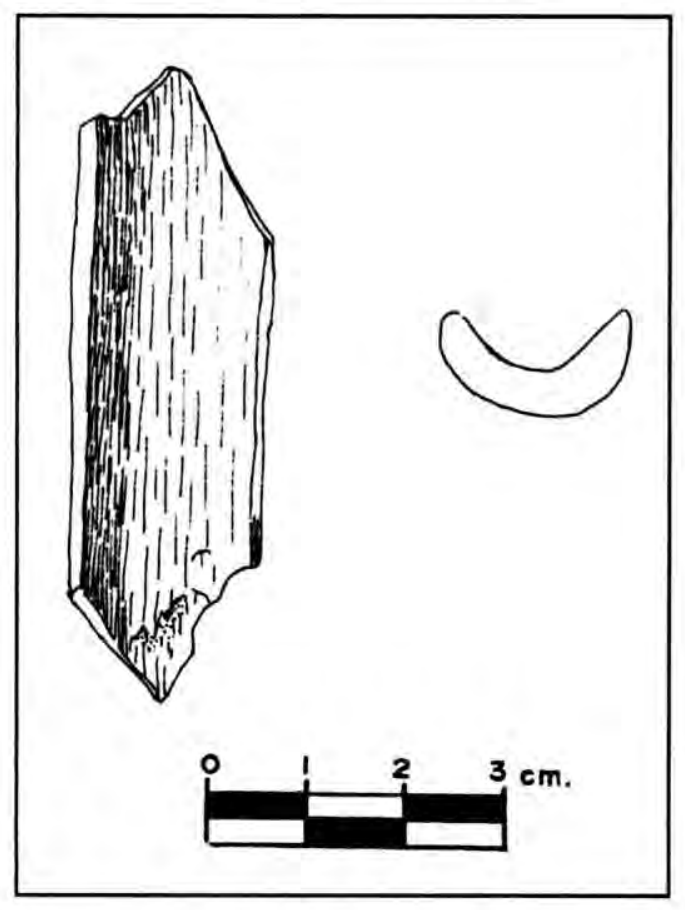

Figura 7. Cuchara de hueso.

\section{Tableta de rapé}

Seis fragmentos de una tableta de rapé en hueso fueron recuperados con el contexto. Son planos, con un espesor de $4 \mathrm{~mm}$, sumamente deteriorados y presentan rastros de cinabrio en una de sus caras. La tableta posiblemente fue confeccionada en hueso de ballena.

Uno de los fragmentos de esta tableta presenta tonalidad verdosa debido al contacto con metal (probablemente el disco de cobre).
Ejemplares de tabletas de rapé han sido reportados en sitios de la costa, como Puerto Supe (Burger: 1992, fig. 56). En ese caso se trataba de un ejemplar con el diseño de un cangrejo estilizado y estaba asociado a un entierro excavado por Max Uhle en 1905 (Kroeber 1925, 1944: 40, 119). Igualmente en contextos de Chilca Pueblo 1 y llegan hasta el Formativo (Engel 1988).

\section{Huesos cortados}

Una serie de fragmentos de huesos tubulares huecos, cortados de manera plana y que en algunos casos presentan huellas de cinabrio en su exterior. Éstos miden aproximadamente entre 9 a $12 \mathrm{~cm}$ de largo.

Se trata de huesos largos donde el corte ha sido efectuado en la parte superior.

De acuerdo a Denise Pozzi-Escot, éstos corresponden a huesos de mamífero. El resto del hueso no evidencia huellas de cortes típicos por consumo humano.

Tello (1960: 353 - 354 y Fig. 177a) describe tubos cilíndricos de hueso a los cuales les otorga una función ritual. Uno de los tubos descritos (177a) es un tubo cilíndrico tallado y grabado con un jaguar mitológico; éste posee un conducto de $14 \mathrm{~mm}$. Un segundo ejemplar (177b) ha sido fabricado de una falange humana tallada con diseños incisos y fue hallado en el piso de la Galería VIII, sobre el ídolo del Lanzón.

\section{Sonaja escultórica de hueso}

Una pequeña y excepcional escultura de hueso finamente labrada, lamentablemente incompleta, también forma parte del hallazgo (Foto 13, Figura 8). Tiene forma tubular y presenta decoración esculpida en la parte superior; la parte baja es tubular. 


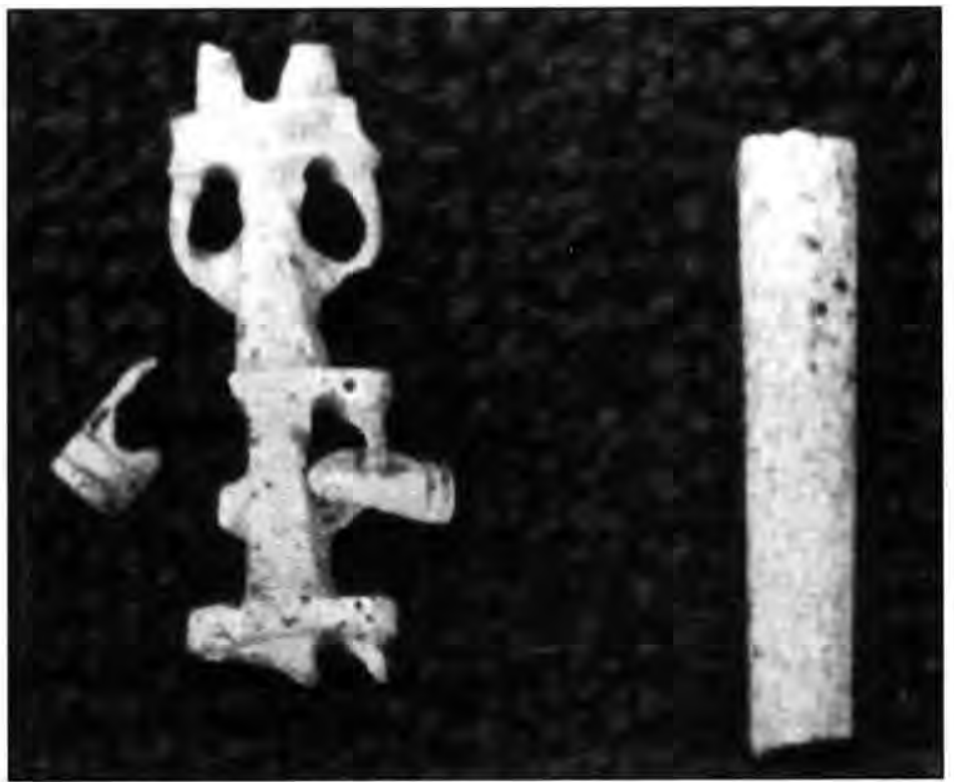

Foto 13. Sonaja de hueso.

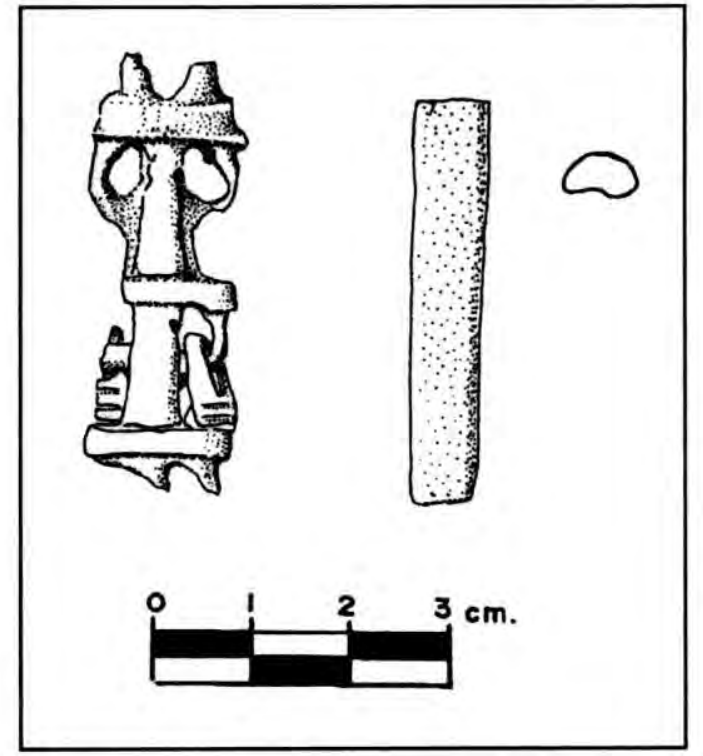

Figura 8. Sonaja de hueso.

Tiene una altura total de $85 \mathrm{~mm}$, la parte decorada mide $45 \mathrm{~mm}$ de altura y $20 \mathrm{~mm}$ de ancho máximo.

El pulido de la pieza ha sido muy fino, lo que ha permitido que de una sola pieza se logren elementos colgantes.

Este ejemplar recuerda a la "sonaja" de hueso procedente de un entierro importante de un "chamán" en Morro Eten, costa de Lambayeque (Elera 1986).

\section{Escultura de hueso}

Se trata de un fragmento de escultura fabricada en hueso; destaca el diseño de un rostro en posición de perfil (Figura 9). La forma podría indicar que fue hecha sobre la base de un asta de venado.

Esculturas de hueso son relativamente comunes en la literatura arqueológica. Destacan los ejemplares descubiertos por Julio C. Tello en Pallka y Chavín de Huántar (Lumbreras 1987), así como los de Cupisnique y Pacopampa, que se encuentran entre los más finos (Burger: 1992 Fig. 228).

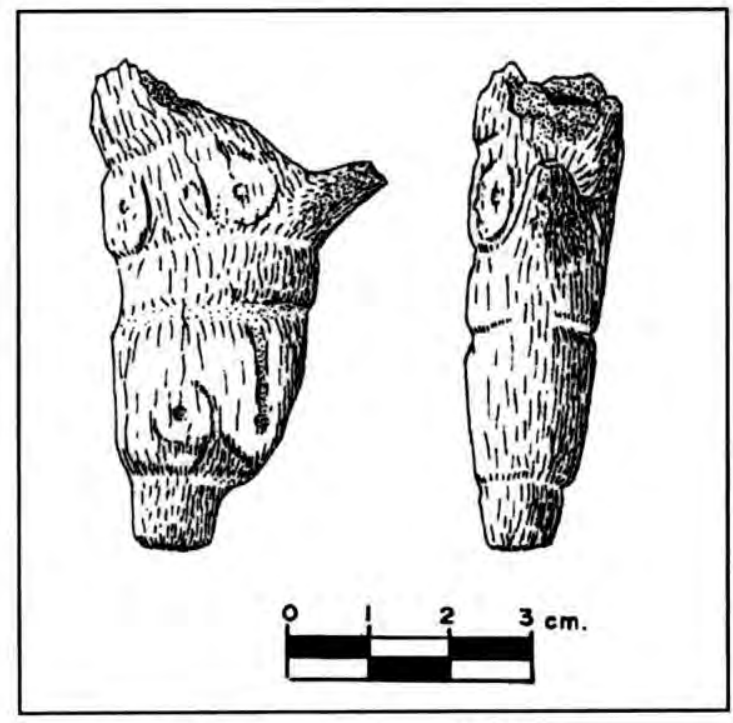

Figura 9. Escultura de hueso. 


\section{Disco de cobre}

Un disco de cobre de $57 \mathrm{~mm} \times 58 \mathrm{~mm}$ de diámetro que presenta hendiduras en el borde al parecer formó parte del contexto. El disco presenta rastros de una pátina roja, probablemente de cinabrio, en una de sus caras. La cara posterior muestra improntas de tejido llano.

Objetos de cobre para el período Formativo han sido hallados en la costa central, en los sitios monumentales de Manchay y Mina Perdida (Burger 1998). Respecto del Formativo Tardío, son muy abundantes principalmente en Tablada de Lurín, de acuerdo a los trabajos de Mercedes Cárdenas.

\section{DISCUSIÓN}

Los sitios correspondientes al período Formativo se ubican principalmente en el valle bajo de Asia, ocupando el amplio cono de deyección del río Asia. Se caracterizan por presentarse a manera de montículos o conchales que se distribuyen entre el kilómetro 97 al 101 (Fotos 14 y 15), es decir, un amplio asentamiento que tiene un área de ocupación de hasta cuatro kilómetros de largo y casi medio kilómetro de ancho. $\mathrm{Si}$ bien en el sitio descrito no se observan estructuras a manera de montículos, esto podría indicar que se trata de un extenso sitio aldeano. De acuerdo a Engel, se trataría de una sociedad que aprovecha las zonas pantanosas para los cultivos (Engel 1966: 42). El mismo autor señaló la existencia de un templo que fue arrasado y que tenía características similares a las de Punkuri en el valle de Nepeña (op. cit. p. 43).

En ese sentido podemos indicar que, a diferencia de la costa central y norcentral, donde el período Formativo se caracteriza por la presencia de grandes conjuntos monumentales conocidos como Templos en forma de "U", a partir de Asia hacia el sur no se han identificado edificaciones monumentales. Esto podría significar una diferenciación en los niveles organizativos y de desarrollo; sólo futuras investigaciones podrán discutir con mayores argumentos esta problemática.

Este período en el valle de Asia representó una tradición arquitectónica diferente que el de la costa central, donde el valle de Lurín parece ser el límite sur de esta característica.

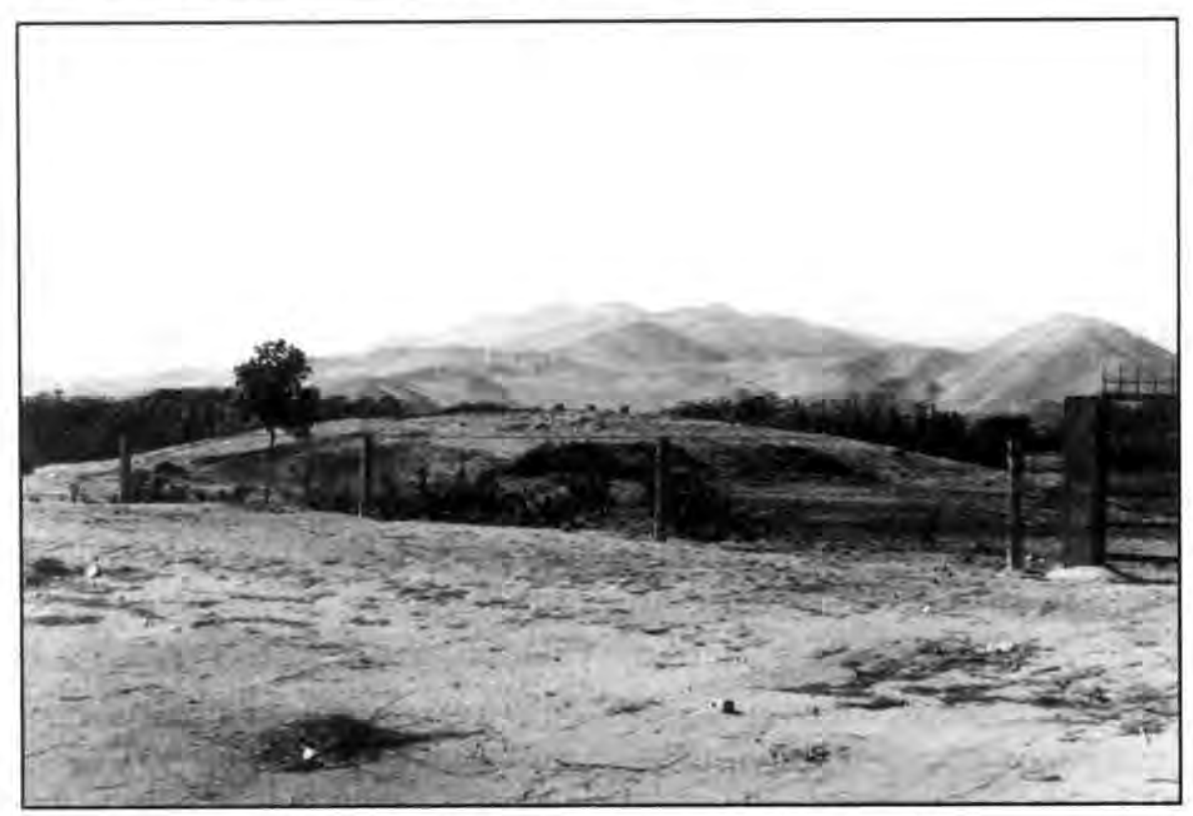

Foto I4. Montículo formativo en el kilómetro 99. 


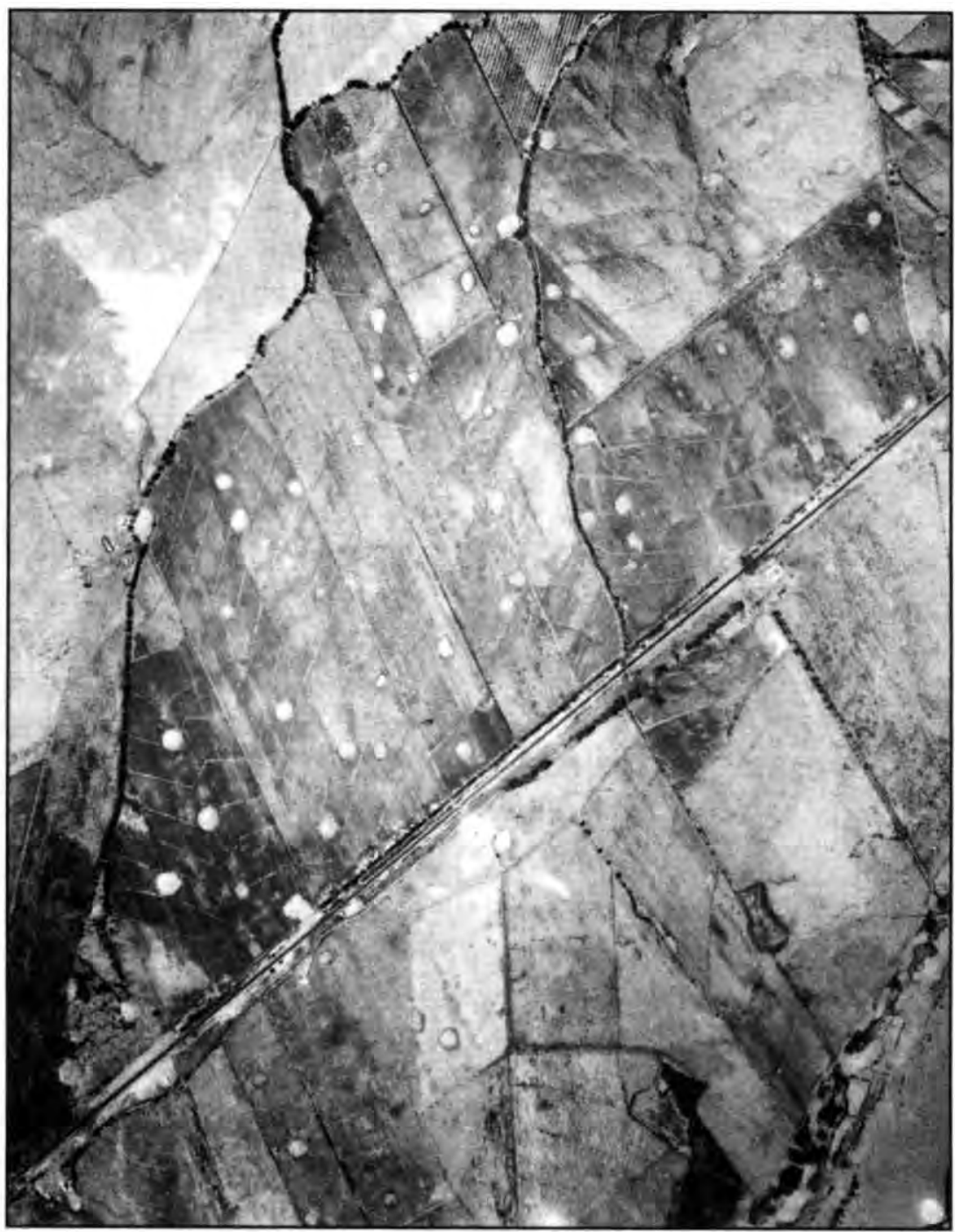

Foto 15. Fotografía aérea que muestra los montículos formativos de un sector del valle bajo de Asia. SAN $351,26.05 .71$.

En Chilca, de acuerdo a Engel (1966), existen "pueblos" con cerámica "Chavín". De ésta se describe un cuenco de paredes altas, labio biselado y decoración incisa externa, proveniente del sitio $12 \mathrm{~B}$, VII 24 , así como una botella de cuerpo globular y gollete, labio biselado que se relacionaría con el Horizonte Temprano (op. cit. Figs. 27 y 28). En el caso del valle de Mala, por ejemplo, las evidencias deben ser debidamente analizadas, ya que no se reconocen materiales del Formativo. El sitio El Salitre (26 j 6K 10 en el registro de Williams y Merino, 1976), donde se registra una estructura piramidal con pozo circular hundido, se halla con una fuerte ocupación tardía en la zona; inclusive el pozo presenta estructuras de adobe correspondientes al Horizonte Tardío, lo que dificulta comprobar los datos para las tempranas ocupaciones.

El singular hallazgo del kilómetro 101, muestra una serie de elementos culturales correspondientes al Período Formativo.

La obsidiana jugó un rol de importancia durante el Horizonte Temprano (Burger 1987). Si bien mayormente han sido reportadas lascas de este material en sitios como Garagay, Ancón, Chavín de Huántar, etc., destaca el hallazgo efectuado por Jorge Silva relacionado con la Fase $\mathrm{C}$ de Huachipa 
(Silva 1997). Grossman en Huayhuaca reporta puntas de obsidiana asociadas al Período Inicial (Burger 1992, Fig. 69).

La inusual abundancia de puntas de proyectil de obsidiana asociadas a este contexto, de acuerdo a Richard Burger y Lucy Salazar representa un conjunto único a la fecha. Consideran que este material puede proceder con seguridad de Ayacucho, de la fuente Quispisisa (Burger 2001).

Generalmente el hallazgo de obsidiana para este período es mayormente de lascas o fragmentos tales como los hallados en Ancón. Sorprende un contexto con esta inusual cantidad de piezas de este tipo, por lo que se plantea que la persona que utilizó esos elementos cumplía un rol diferenciado en su comunidad. La obsidiana no es un material adecuado para ser lanzado como punta de proyectil; éste resulta frágil. En la medida en que es la forma la que prima al acabado de detalles, consideramos que su uso es probable que fue ritual antes que de cacería.

Un conjunto de puntas de obsidiana hallado en contexto Paracas correspondía, de acuerdo a Tello, al instrumental de un cirujano.

La punta de doble muesca basal es única, por lo que al parecer no es un instrumento de uso cotidiano en el período Formativo. Los espejos, por su parte, sí forman parte de los hallazgos para este período, pero indican un probable uso ritual al igual que la obsidiana.

La sonaja reportada por Carlos Elera para un entierro principal de Morro Eten, permitió postular de que el individuo se trataba de un chamán.

Una tableta de rapé ha sido reportada para el mismo período en el valle de Supe por Uhle (Kroeber 1925; Menzel 1977; Burger 1992).
De acuerdo a las asociaciones, este hallazgo corresponde a una tumba (puntas de obsidiana, espejo de antracita, hacha pulida, sonaja de hueso, escultura de hueso, punta atípica, fragmentos de tableta de rapé, cuchara, etc.). La tumba podría pertenecer a un chamán u oficiante relacionado con el culto, en la medida que incluye tubos para inhalar, tableta de rapé, la serie de puntas de obsidiana y adornos de hueso relacionados con probabilidad a su parafernalia. Varios de estos objetos son exóticos y selectivos. Elementos de este contexto formarían parte de la indumentaria y de los objetos que estarían asociados a su función especializada dentro de su comunidad. Es posible que varias clases de estos objetos estuvieran involucrados en la preparación y en la ingestión de alucinógenos, tal como plantea para otros contextos Richard Burger (1992: 165-166).

Si de acuerdo a Richard Burger (1992) las sociedades constructoras de los complejos cívico-ceremoniales con planta en forma de " $U$ " eran unidades políticamente independientes pero culturalmente relacionadas, la inexistencia de tales centros cívicos en valles como Chilca o Asia necesita una explicación diferente a lo que sucede en la costa central. Sin embargo la cerámica procedente de esta zona sí presenta vinculaciones con la costa central, en este caso debemos entender que existen relaciones culturales más un sistema político aún no definido, pero explicable por la falta de estudios correspondientes a este período. Las botellas descritas así como la presencia de ollas sin cuello en los conchales del valle bajo indican una fuerte relación con la costa central. Es necesario realizar excavaciones en el valle que permitan clarificar la secuencia cronológica de este período.

Los materiales asociados a esta tumba indican que el valle de Asia no fue ajeno al tráfico de ideologías e interacción de las so- 
ciedades costeñas y serranas durante este período en el que los aspectos ideológicos jugaron un rol fundamental.

El principio de acceso a productos exóticos o cargados de "ideología" estuvo ligado a aquellos que debieron cumplir funciones relacionadas al culto o a quienes obtuvieron un grado de diferenciación social o de status debido a su edad, su conocimiento o su acceso a información especializada relacionada a prácticas chamánicas; en ese contexto se insertaría el "hacha pulida",

Estamos al parecer frente a los objetos pertenecientes a la tumba de un personaje de prestigio que tuvo acceso, ya sea por su edad, función en su comunidad u otras razones que desconocemos, a elementos relacionados con la ideología y la superestructura. Tumbas o contextos de este tipo son escasos, a excepción de la tumba reportada por Carlos Elera en Morro Eten. Varios de esos elemen- tos aparecen aislados, en sitios como Ancón, y debido a la forma de la vasija descrita, entre otros, podemos insinuar que durante el período Formativo las poblaciones que habitaban el valle de Asia se hallaban insertas en el sistema ideológico de la costa central, con la que compartían rasgos culturales durante la expansión de rasgos Chavín. La obsidiana y los espejos de antracita, por ejemplo, fueron de uso ritual, ya que éstos no evidencian uso y no son comunes en otros contextos funerarios reportados para otras zonas. Lo que implica tener acceso a estos materiales, así como comprender su delicada y precisa manufactura, son elementos que no debemos descuidar en el análisis de los contextos de clase o diferenciación social o funcional.

Si bien la información presentada es bási$\mathrm{ca}$, estos elementos nos permiten insertar al valle de Asia en la discusión del denominado Horizonte Chavín.

\section{AGRADECIMIENTOS}

Expresamos nuestro sincero agradecimiento a Elmo León, por el apoyo en el análisis del material lítico; a Luis G. Lumbreras, por sus importante apreciaciones en la revisión del material.

A Richard Burger y Lucy Salazar de Burger, por sus valiosos comentarios; a Denise Pozzi-Escot, por el apoyo en la identificación del material óseo animal. A Jorge Silva y Jonathan Palacios.
A Daniel Cabrel y Julio Abanto, que colaboraron con los dibujos del material lítico y óseo, nuestro sincero agradecimiento.

A la Municipalidad de Asia y en especial a su alcalde José Arias por el apoyo prestado.

Finalmente, al Museo de Arqueología y Antropología de la Universidad Nacional Mayor de San Marcos y en especial a su directora Ruth Shady Solís por la publicación. 


\section{BIBLIOGRAFÍA}

ÁNGELES FALCÓN; Rommel y Denise POZZI-ESCOT

2000 "Investigaciones arqueológicas en Huaca Malena, valle de Asia". En Arqueológicas 24. Órgano del Instituto de Investigaciones Museo Nacional de Arqueología, Antropología e Historia del Perú. Instituto Nacional de Cultura.

\section{BURGER, Richard y Frank ASARO}

1979 Análisis de rasgos significativos en la obsidiana de los Andes Centrales. En Revista del Museo Nacional, tomo XLIII (1977), pp. 281-325. Lima.

BURGER, Richard

1992 Chavin and the Origins of Andean Civilization. Thames and Hudson

1998 "Early Central Andean Metalworking from Mina Perdida", Perú. En Science, Vol. 282.

\section{DUMBARTON OAKS}

1996 Andean Art at Dumbarton Oaks, Vol. 1. Elizabeth Hill Boone, Editor. Dumbarton Oaks Research Library and Collections. Washington DC.

ELERA, Carlos G.

1986 Investigaciones sobre patrones funerarios en el sitio Formativo del Morro Eten, valle de Lambayeque, costa norte del Perú. Tomos I - II Memoria de Bachiller. Pontificia Universidad Católica del Perú. Facultad de Letras y Ciencias Humanas.

\section{ENGEL, Frederic}

1963 A preceramic Settlement on the Coast of Peru: Asia Unit 1. Transactions of the American Philosophical Society 53 (3).

1966 Geografía Humana Prehistórica y Agricultura Precolombina de la Quebrada de Chilca I. Informe Preliminar. Universi- dad Agraria. Oficina de Promoción y Desarrollo. Departamento de Publicaciones. Lima.

1987 De las begonias al maíz. CIZA Centro de Investigación de las Zonas áridas. Lima.

1987 Ecología Prehistórica Andina: Chilca pueblo 1, implementos de hueso. CIZA. Universidad Agraria La Molina, Lima.

LUMBRERAS, Luis Guillermo 1989 Chavín de Huántar en el Nacimiento de la Civilización Andina. Ediciones INDEA. Instituto Andino de Estudios Arqueológicos. Lima.

\section{ONERN}

1976 Inventario, evaluación y uso racional de los recursos naturales de la Costa-Cuencas de los ríos Chilca, Mala y Asia. Oficina Nacional de Evaluación de Recursos Naturales. Ministerio de Agricultura, Lima.

ROSAS, Hermilio

1970 La secuencia cultural del período Formativo en Ancón. Tesis de Grado en el programa Académico de Psicología y Ciencias Sociales. Universidad Nacional Mayor de San Marcos. Lima.

SCHEELE, $\mathrm{H}$.

1970 The Chavin Occupation of the Central Coast of Peru. Ph. D. Dissertation, Department of Anthropology, Harvard University, Cambridge.

SILVA Jorge, Keneth HIRTH, Rubén GARCÍA y José PINILLA

1983 "El Formativo en el Valle del Rímac: Huachipa - Jicamarca". En Arqueología y Sociedad $\mathrm{N}^{\circ}$ 9. Museo de Arqueología y Antropología de la Universidad Nacional Mayor de San Marcos, Lima. 
TELLO, Julio C.

1960 Chavin, cultura matriz de la civilización Andina. Primera parte. Publicación Antropológica del Archivo "Julio C. Tello" de la Universidad Nacional Mayor de San Marcos. Vol. II. Imprenta Universidad Nacional Mayor de San Marcos, Lima.

WALLACE, Dwight

196 "Early Horizon ceramics in the Cañete Valley of Peru". En Ñawpa Pacha: 3539.
WILLIAMS, Carlos y Manuel MERINO 1976 Inventario, catastro y delimitación del patrimonio arqueológico del valle de Mala. Centro de Investigación y Restauración de Bienes Monumentales. Instituto Nacional de Cultura. Lima.

WILLIAMS, Carlos 1978 Complejos de Pirámides con Planta en "U", patrón arquitectónico de la costa central. En Revista del Museo Nacional, Tomo XLIV, pp. 95-101. Lima. 